\title{
GALLIUM INCORPORATION INTO PHOSPHATE BASED GLASSES: BULK AND THIN FILM PROPERTIES
}

\section{Bryan W. Stuart ${ }^{1}$, Colin A. Grant ${ }^{2}$, George E. Stan ${ }^{3}$, Adrian C. Popa ${ }^{3,4}$, Jeremy J. Titman ${ }^{5}$, David M. Grant ${ }^{1}$}

${ }^{1}$ Advanced Materials Research Group, Faculty of Engineering, University of Nottingham, UK

${ }^{2}$ School of Chemistry and Biosciences, University of Bradford, BD7 1DP, UK

${ }^{3}$ National Institute of Materials Physics, Magurele-Ilfov, Romania

${ }^{4}$ Army Centre for Medical Research, RO-010195 Bucharest, Romania

${ }^{5}$ School of Chemistry, University of Nottingham, UK

\begin{abstract}
:
The osteogenic ions $\mathrm{Ca}^{2+}, \mathrm{P}^{5+}, \mathrm{Mg}^{2+}$, and antimicrobial ion $\mathrm{Ga}^{3+}$ were homogenously dispersed into a $1.45 \mu \mathrm{m}$ thick phosphate glass coating by plasma assisted sputtering onto $\mathrm{CP}$ grade titanium. The objective was to deliver therapeutic ions in orthopedic/dental implants such as hip prosthesis or dental screws. The hardness $4.7 \mathrm{GPa}$ and elastic modulus $69.7 \mathrm{GPa}$, of the coating were comparable to plasma sprayed hydroxyapatite/dental enamel, whilst superseding femoral cortical bone. To investigate the manufacturing challenge of translation from a target to vapour condensed coating, structural/compositional properties of the target (P51MQ) were compared to the coating (P40PVD) and a melt-quenched equivalent (P40MQ). Following condensation from $\mathrm{P} 51 \mathrm{MQ}$ to $\mathrm{P} 40 \mathrm{PVD}, \mathrm{P}_{2} \mathrm{O}_{5}$ content reduced from 48.9 to $40.5 \mathrm{~mol} \%$. This depolymerisation and reduction in the P-O-P bridging oxygen content as determined by ${ }^{31} \mathrm{P}-\mathrm{NMR}, \mathrm{FTIR}$ and Raman spectroscopy techniques was attributed to a decrease in the $\mathrm{P}_{2} \mathrm{O}_{5}$ network former and increases in alkali/alkali-earth cations. P40PVD appeared denser (3.47 vs. $2.70 \mathrm{~g} \mathrm{~cm}^{-3}$ ) and more polymerised than it's compositionally equivalent P40MQ, showing that structure/ mechanical properties were affected by manufacturing route.
\end{abstract}

Keywords: Phosphate glass; sputtering; coating; osseointegration; antimicrobial.

*Corresponding author: Bryan W. Stuart; E-mail: bryan.stuart@materials.ox.ac.uk, Tel: $+44-773-4062-920$ 


\section{Introduction}

Phosphate Based Glasses (PBG) gradually resorb in aqueous media whilst releasing a custom array of ionic constituents making them desirable for potential biomedical applications, from resorbable composites for fracture fixation to therapeutic ion carriers [1]. A Web of Science ${ }^{\mathrm{TM}}$ search for "phosphate glass" returned over 13,000 publications since 1984, when Bunker et al. reported on their dissolution capabilities in aqueous media [2]. To date, neither the U.S. Food and Drug Administration (FDA) nor U.K. Medicines and Healthcare products Regulatory Agency have regulated a single device containing PBG components. In comparison, the clinical applicability of 45S5 silicate based bioglass developed by Larry Hench in 1969 obtained FDA (510 k) approval in six applications from 1985 to 2012. These included an Ossicular Reconstruction Prosthesis (1985), orthopaedic bone graft and toothpaste additives, known as Novabone (2000) and Novamine (2004), respectively [3]. The research here developing orthopaedic glasses deposited as a multifunctional orthopaedic coating may for the first time enable utilisation on load bearing materials and lead to a modern stratified approach to facilitating osseointegration, preventing bone degeneration or for combatting infection around implant sites in applications which include total hip prosthesis or dental screws $[4,5]$.

A PBG is composed of a three-dimensional covalent backbone (network) of tetrahedral $\mathrm{PO}_{4}{ }^{3-}$ units bound together by $\mathrm{P}-\mathrm{O}-\mathrm{P}$ bridging oxygens or by multivalent non-bridging ionic constituents [6]. By convention the structure may be defined by the number of $\mathrm{Q}^{\mathrm{n}}$ units within the glass, where $n=0-3$, representing the number of bridging oxygens per tetrahedron [6]. Dissolution rates of PBG structures may be controlled by orders of magnitude by inclusion of intermediate elements such as $\mathrm{Ti}^{4+}, \mathrm{Fe}^{3+}$ or $\mathrm{Ga}^{3+}$ which can either play network modifiers roles, depolymerising the glass structure through ionic cross linking or infiltrate and stabilise the backbone, creating hydration resistance through $\mathrm{P}-\mathrm{O}-\mathrm{Ti}, \mathrm{P}-\mathrm{O}-\mathrm{Fe}$ or P-O-Ga type bonds [7, 8].

Ions including $\mathrm{Ca}^{2+}, \mathrm{Sr}^{2+}, \mathrm{P}^{5+}$, and $\mathrm{Mg}^{2+}$ have been shown to stimulate osteoblast cell proliferation and differentiation towards mineralisation of regenerated cortical bone whilst the "potent" antimicrobial potential of $\mathrm{Ga}^{3+}$ was reported by Knowles and his coworkers [9-12]. Valappil et al. reported on the positive efficacy of $1-5 \mathrm{~mol} \%$ of $\mathrm{Ga}_{2} \mathrm{O}_{3}$ incorporated into a melt-quenched PBG composition (mol\%: 45- $\mathrm{P}_{2} \mathrm{O}_{5}, 16-\mathrm{CaO}, 34-$ $\mathrm{Na}_{2} \mathrm{O}, 5-\mathrm{Ga}_{2} \mathrm{O}_{3}$ ) against Escherichia coli, Pseudomonas aeruginosa, Staphylococcus aureus and Clostridium difficile. $\mathrm{Ga}^{3+}$ possesses the ability to inhibit bacterial 
development as similar atomic radii and equivalent trivalency lead to the bacteria's inability to distinguish between $\mathrm{Fe}^{3+}$ and $\mathrm{Ga}^{3+}$ known as the "Trojan Horse effect" [13]. Microorganisms exploit the redox reaction of $\mathrm{Fe}^{3+} / \mathrm{Fe}^{2+}$ for electron harvesting [14]. The inability to distinguish and reduce $\mathrm{Ga}^{3+}$ starves the cell resulting in apoptosis [13].

Stan et al. and Stuart et al. utilised Radio-frequency Magnetron Sputtering (RFMS), a Physical Vapour deposition (PVD) method, to deposit layers ranging in thickness from $200 \mathrm{~nm}$ to $25 \mu \mathrm{m}$ of silicate- and phosphate-based glasses respectively onto pure titanium (Ti) and Ti alloy implant materials [4, 15]. PVD based technologies such as plasma spray $[16,17]$, pulsed laser deposition [18, 19], or RFMS allows glasses to be applied uniformly to load bearing surfaces such as hip stems or dental screws to utilise their osteogenic and ion leaching potential. Furthermore, magnetron sputtering enables the fabrication of mechanically reliable films [20, 21], fulfilling the requirements of ISO-137792 Part 2 "Coatings of Hydroxyapatite" [22] and the 1994 FDA draft guidance for $\mathrm{Ca} / \mathrm{P}$ coatings on medical implants [23], whilst process optimisation may supersede all reported methodologies with respect to interfacial adherence $[5,24]$. Its potentially low temperature $\left(<70^{\circ} \mathrm{C}\right)$ operating conditions allows for deposition onto medical materials from metals to temperature-sensitive polymers [25, 26].

The composition (mol \%) $\mathrm{P}_{2} \mathrm{O}_{5}-40 \mathrm{CaO}-16 \mathrm{MgO}-24 \mathrm{Na}_{2} \mathrm{O}-16 \mathrm{Fe}_{2} \mathrm{O}_{3}-4$ has shown superior biocompatibility as an orthopaedic ion leaching glass due to the presence of 4 mol\% $\mathrm{Fe}_{2} \mathrm{O}_{3}$ as a trivalent cross-linking and intermediate oxide [27]. To produce an antibacterial composition, $\mathrm{Fe}_{2} \mathrm{O}_{3}$ was replaced here by $\mathrm{Ga}_{2} \mathrm{O}_{3}$ (having a similar structural role), resulting in the $\mathrm{P}_{2} \mathrm{O}_{5}-40 \mathrm{CaO}-15 \mathrm{MgO}-24 \mathrm{Na}_{2} \mathrm{O}-15 \mathrm{Ga}_{2} \mathrm{O}_{3}-6$ formulation, labelled P40MQ or P40PVD, depending on the fabrication route. However, the effects of preferential sputtering lead to non-stoichiometric atomic transfer from the target material to the as-deposited thin film as discussed elsewhere $[28,29]$. In particular, a significant reduction in phosphorous (i.e., from $\sim 11$ to $15 \mathrm{~mol} \%$, depending on the sputtering parameters) has been found. Therefore, a target composition, richer in $\mathrm{P}_{2} \mathrm{O}_{5}$, i.e. $\mathrm{P} 51 \mathrm{MQ}$, was sputtered to produce the P4OPVD coatings. The primary aim was to evaluate the physical-chemical and mechanical modification as the glass is transferred from the meltquenched target to the condensed thin film. Similarly the difference in properties between compositionally similar P40MQ and P40PVD is of great interest in future manufacturing and performance of implant glass thin films.

The secondary aim of the work presented here was to demonstrate the ability to incorporate osteogenic $\left(\mathrm{Ca}^{2+}, \mathrm{P}^{5+}, \mathrm{Mg}^{2+}\right)$ [9] and antimicrobial $\left(\mathrm{Ga}^{3+}\right)$ [10] ions in 
quaternary PBG thin films onto medically relevant commercially pure Ti. The mechanical properties were assessed by nano-indentation. The majority of studies in the implant coatings area have focused on the identification of technological recipes capable of meeting the ISO standards and FDA requirements for the stipulated minimum pull-off adhesion of 15 and $50.8 \mathrm{MPa}$ [22, 23] mandatory for load-bearing hydroxyapatite (HA) layers. This test, although useful for comparison is suboptimal due to the diversity of clinical failure modes. Therefore, due to the highly adherent nature of sputtered (hydroxyapatite and bio-glass) films, [5, 30], the elastic modulus and hardness properties were investigated by nano-indentation methods. This, in conjunction with detailed characterisation through NMR, ellipsometry, IR and Raman spectroscopy and TEM allows a deeper understanding of the thin film coatings potential for clinical applications and insight towards the mechanical performance of an implant coating, as abrasion during implantation or in vivo micro-motion may lead to particulate spallation and aseptic loosening [31, 32]. Nano-indentation is commonly used to measure the elastic modulus and hardness of a test sample[33], for example Leyland et al. used ratios of hardness to elastic modulus, obtained by nano-indentation measurements, to infer plasticity, toughness and abrasive resistance [34].

The collected information could serve as gauge for the potential of PBG coatings to be integrated in the design of a next generation of bio-functional implant structures.

\section{Materials and Methods}

\subsection{Substrate preparation}

Substrates were $1 \mathrm{~mm}$ thick, $10 \mathrm{~mm}$ diameter discs of commercially pure $\mathrm{Ti}$ (cp-Ti, grade 1), wire-eroded from a sheet. Discs were first wet polished with abrasive SiC papers of different grit size (from P200 to P4000), followed by a final polishing stage using a 0.25 $\mu \mathrm{m}$ chemomet-finishing pad (Struers ${ }^{\circledR}$ ) with the application of colloidal silica. The substrate roughness was measured as $4.2 \pm 0.8 \mathrm{~nm}(\mathrm{n}=5$ samples) by Atomic Force Microscopy over a scan area of $20 \times 20 \mu^{2}$. Alternatively, double-side mirror polished Silicon (100) substrates were used for optical investigation of coatings.

\subsection{Melt Quenched Glass Fabrication}

Pre-calculated (mol\%) proportions of the glass precursors namely, Sodium Dihydrogen Phosphate $\left(\mathrm{NaH}_{2} \mathrm{PO}_{4}\right.$, Sigma Aldrich, St. Louis, MO, USA, purity >99\%), Calcium Hydrogen Phosphate $\left(\mathrm{CaHPO}_{4}\right.$, Sigma Aldrich, St. Louis, MO, USA, 98-105\%), Magnesium Phosphate Dibasic Trihydrate $\left(\mathrm{MgHPO}_{4} \cdot 3 \mathrm{H}_{2} \mathrm{O}\right.$, Sigma Aldrich, St. Louis, 
MO, USA, >97\%), Phosphorous Pentoxide $\left(\mathrm{P}_{2} \mathrm{O}_{5}\right.$, Thermo Fisher, Loughborough, UK, $>98 \%)$ and Gallium Oxide $\left(\mathrm{Ga}_{2} \mathrm{O}_{3}\right)$, Sigma Aldrich, St. Louis, MO, USA, >99.99\%), were thoroughly mixed in their powdered forms, then preheated at $400{ }^{\circ} \mathrm{C}$ in a $\mathrm{Pt}: \mathrm{Rh}(90: 10 \%)$ crucible for 30 min to dehydrate. For P51MQ production the mixture was then melted at $1200{ }^{\circ} \mathrm{C}$ for $2 \mathrm{~h}$ in air and subsequently quenched into a graphite mould to a target diameter of $75 \pm 2 \mathrm{~mm}$ at $450{ }^{\circ} \mathrm{C}$, followed by natural furnace cooling to room temperature. For P40MQ production the mixture was quenched into $10 \mathrm{~mm}$ diameter rods by the same protocol. Table 1 contains the nominal intended compositions for production of both Melt Quenched (MQ) and Physical Vapour Deposited (PVD) glasses.

Table 1: Nominal sample compositions to produce MQ and PVD glasses. P51MQ was utilised as a sputtering target to condense P4OPVD. The compositional equivalent of $P 40 P V D, P 40 M Q$, was produced for comparison.

\begin{tabular}{l|c|c|c|c|c}
\hline & \multicolumn{5}{|c}{ Oxide composition (mol\%) } \\
\hline & $\mathbf{P}_{2} \mathbf{O}_{5}$ & $\mathbf{C a O}$ & $\mathbf{M g O}$ & $\mathrm{Na}_{2} \mathbf{O}$ & $\mathbf{G a}_{2} \mathbf{O}_{3}$ \\
\hline P51MQ & 51.5 & 14.0 & 18.5 & 10.0 & 6.0 \\
\hline P40MQ & 40.0 & 15.0 & 24.0 & 15.0 & 6.0 \\
\hline
\end{tabular}

\subsection{Coating deposition process}

Coatings were deposited via a custom in-house designed magnetron sputtering rig built at the University of Nottingham, utilising a $75 \pm 2 \mathrm{~mm}$, water cooled planar magnetron. The chamber was pumped down to high vacuum by combination of a rotary (Edwards E2M-18) and turbo-molecular (Edwards EXT250) pumps. The attained base pressure was below $7 \times 10^{-3} \mathrm{~Pa}$. The substrates were fixed at a distance of $40 \pm 2 \mathrm{~mm}$ from the target surface. The argon (purity $99.99 \%, \mathrm{BOC}^{\odot}$ ) flow was controlled via a mass flow controller (MKS 2982) and a pressure controller (MKS 250), and monitored by a temperature controlled capacitive pressure transducer (MKS Baratron 627B). The P51MQ target was argon ion bombarded under a Radio Frequency (RF) (13.56 MHz) power supply. A working pure argon pressure of $1.33 \mathrm{~Pa}$ has been employed in all experiments. The target was pre-cleaned for a minimum of $30 \mathrm{~min}$ at $30 \mathrm{~W}$, and then increased to $60 \mathrm{~W}$ for a further $30 \mathrm{~min}$, allowing sufficient time for the target's temperature along with the sputtering processes to stabilise prior to the actual coating deposition. Coatings were deposited for $20 \mathrm{~h}$ to produce a thickness of $\sim 1450 \mathrm{~nm}$.

\subsection{Characterization techniques}

Spectroscopic ellipsometry (SE) 
Coating thickness measurements, Cauchy coefficients and refractive indices were acquired on a JA Woolam M-2000 ellipsometer at variable angle of 55, 60 and $65^{\circ}$ and was modelled using CompleteEASE via application of the Cauchy equation. Four measurements were obtained on each sample at an approximate distance of $2 \mathrm{~mm}$ apart and modelled at wavelengths of $190-1690 \mathrm{~nm}$.

\section{Energy Dispersive X-Ray (EDX) Spectroscopy}

The compositions of the sputtering targets and sputtered coatings were determined by EDX spectroscopy, using an Oxford Instruments apparatus attached to a Phillips XL30 scanning electron microscope (SEM), by averaging the composition analysis of $n=4$ randomly chosen locations of $30 \times 30 \mu \mathrm{m}^{2}$.

EDX spectroscopy elemental mapping was conducted at a working distance of $10 \mathrm{~mm}$ for $300 \mathrm{~s}$ with a beam voltage of $15 \mathrm{kV}$. The electron beam current was optimized by increasing the spot size to obtain a minimum acquisition rate of 4000 counts $\mathrm{s}^{-1}$, while maintaining an acquisition dead time lower than $30 \%$.

Cross sectional coating images were obtained using a Jeol Field Emission Gun (FEG)SEM with a beam voltage of $15 \mathrm{kV}$. The coated cp-Ti disc was embedded in resin and the interface was polished with $\mathrm{SiC}$ paper grades 240 -to-4000 prior carbon coating and SEM imaging.

\section{X-Ray Diffraction (XRD)}

P51MQ and P40MQ target were grounded for powder XRD (symmetric $\theta-\theta$ geometry) analysis, utilising a (Bruker D8, $\mathrm{Cu} \mathrm{K}_{\alpha}$ source, $\left.\lambda=1.5418 \AA, 40 \mathrm{kV}, 40 \mathrm{~mA}\right)$ conducted over a $2 \theta$ range from $15^{\circ}$ to $65^{\circ}$, with a step size of $0.04^{\circ}$ and a dwell time of $5 \mathrm{~s}$. Additionally, the crystalline status of the P40PVD coating was assessed by grazing incidence XRD (GIXRD), using the same apparatus. The incidence angle was set at $2^{\circ}$, and the scattered intensity was scanned in the same $2 \theta$ angular range, with a step size of $0.02^{\circ}$, and $10 \mathrm{~s}$ per step. The small incidence angle allows for an increase beam path in the sample, with the direction of the scattering vector no longer perpendicular to the sample surface, which makes the diffraction analysis in this asymmetric geometry more surface sensitive.

\section{Nuclear Magnetic Resonance (NMR) Spectroscopy}

Quantitative ${ }^{31} \mathrm{P}$ NMR spectra were recorded at room temperature on a Bruker Advance III spectrometer at a Larmor frequency of $242.94 \mathrm{MHz}$ using a $2.5 \mathrm{~mm}$ magic-angle spinning (MAS) probe spinning at $25 \mathrm{kHz}$. The $31 \mathrm{P} \pi / 2$ pulse duration was $3.5 \mu$ s, the 
spectral width was $200 \mathrm{kHz}$ and the acquisition time was $5.12 \mathrm{~ms}$. Chemical shifts are quoted relative to $85 \% \mathrm{H}_{3} \mathrm{PO}_{4}$. Prior to acquiring ${ }^{31} \mathrm{P}$ spectra the spin-lattice relaxation time $T_{1}$ was determined for each sample by saturation recovery. Saturation was achieved by $10031 \mathrm{P} \pi / 2$ pulses spaced by delays of $20 \mathrm{~ms}$ with recovery delays of between $10 \mathrm{~s}$ and $1000 \mathrm{~s}$. Quantitative 31P NMR spectra required relaxation delays (5 T1) of the order of $350 \mathrm{~s}$ for the films and up to $600 \mathrm{~s}$ for the bulk samples. The resulting spectra were deconvoluted into a set of Gaussian line shapes which were integrated in order to quantify the proportions of the different $\mathrm{PO}_{4}{ }^{3-}$ tetrahedral environments in the sample. First-order MAS sidebands were included in the analysis.

\section{Fourier Transform Infrared (FTIR) spectroscopy}

A Bruker Tensor FTIR spectrometer with an attenuated total reflectance (ATR) attachment with diamond/ZnSe crystal plate was used for all IR absorption measurements. A spectral resolution of $4 \mathrm{~cm}^{-1}$ over the wavenumber range 500-4000 $\mathrm{cm}^{-1}$ was set. All spectra obtained represent the average of 64 scans. P51MQ and P40MQ were ground to a powder for analysis, whilst coatings were assessed by direct contact of the coating surface and the ATR crystal.

\section{Micro-Raman spectroscopy}

Raman spectroscopy was performed using a HORIBA Jobin Yvon LabRAM HR spectrometer. Spectra were acquired using a $532 \mathrm{~nm}$ laser at $25 \mathrm{~mW}$ power, a $50 \times$ objective, and a $300 \mu \mathrm{m}$ confocal pinhole. To simultaneously scan a range of Raman shifts, a 600 lines $/ \mathrm{mm}$ rotatable diffraction grating along a path length of $800 \mathrm{~mm}$ was employed. Spectra were detected using a SYNAPSE CCD detector (1024 pixels) thermoelectrically cooled to $-60{ }^{\circ} \mathrm{C}$. Prior to spectral collection, the instrument was calibrated using the Rayleigh line at $0 \mathrm{~cm}^{-1}$ and a standard Si (100) reference band at $520.7 \mathrm{~cm}^{-1}$. Spectra were recorded for $20 \mathrm{~s}$ and 20 accumulations.

\section{Atomic Force Microscopy (AFM)}

Topographical features were assessed by AFM using a Bruker Dimension Icon apparatus, equipped with 0.01-0.025 Ohm-cm Antinomy (n) doped Si tips (model TAP525A). All measurements were acquired over five $(n=5)$ randomly selected scan areas of $20 \times 20$ $\mu \mathrm{m}^{2}$. Nano Scope Analysis 1.7 software was used to assess the arithmetic mean roughness $\left(\mathrm{R}_{\mathrm{a}}\right)$. All images were processed using a first-order flattening to remove bowing.

\section{Nano-indentation}


The nano-mechanical properties of all the samples was analysed using a Hysitron TI-950 Nanoindenter. Nanoindentation techniques require a well-defined calibration of the tip area function of the Berkovich indenter. A detailed review of the basic principles, equations and refinements for static nanoindentation technique can be found elsewhere [35]. However, the final equations used by the software to calculate reduced moduli $\left(\mathrm{E}_{\mathrm{r}}\right)$ and hardness $(\mathrm{H})$ data are the following:

$$
E_{r}=\frac{S \sqrt{\pi}}{2 A_{c}} \quad H=\frac{F}{A_{c}}
$$

Where $\mathrm{S}$ is the unloading stiffness at the point of initial unloading, $\mathrm{A}_{\mathrm{c}}$ is the contact area, and $\mathrm{F}$ is maximum load. An array of 10x10 indents were made at the central region, each indentation was $100 \mu \mathrm{m}$ apart, at loads up to $2.5 \mathrm{mN}$, using a constant strain rate loading profile; which means the ratio of the loading rate of the indenter to the measured applied load is a constant. Typical values range between 0.05 and $0.2 \mathrm{~s}^{-1}$ [36], but for this study the value was held constant at $0.1 \mathrm{~s}^{-1}$. This was to eliminate any strain rate dependent effects of the samples, whilst recording reduced modulus and hardness.

All nano indentation and mechanical indices were compared by application of a t-test, utilising a 95\% confidence level $(\mathrm{P}<0.05)$.

\section{Density by Helium Pycnometry and Micro Balance}

Helium pycnometry was carried out using an AccuPyc II 1340 from Micromeritics in $99.9995 \%$ helium at a maximum pressure of $\sim 1.35 \times 10^{5} \mathrm{~Pa}$, utilising an equilibrium rate of $\sim 34.5 \mathrm{~Pa} \mathrm{~g} / \mathrm{min}$. $1.05 \pm 0.05 \mathrm{~g}$ of sample was analysed in a $12.7 \times 10^{3} \mathrm{~mm}^{3}$ sample cell. Samples were purged 10 times followed by 10 cycles to assess skeletal density. In order to extract the coating density, the $10 \mathrm{~mm}$ diameter $\mathrm{cp}$-Ti discs were coated to a thickness of $\sim 1.02 \pm 0.01 \mu \mathrm{m}$ (measured by SE) and weighed pre and post coating using a Sartorius micro balance (ME36S) accurate to $1 \mu \mathrm{g}$. 8 coatings were deposited and measured over 3 independent batches. 


\section{Results}

\subsection{SEM-EDX}

The composition of the P51MQ target $\left[\mathrm{P}_{2} \mathrm{O}_{5}(48.9 \pm 1.4), \mathrm{CaO}(12.1 \pm 0.3), \mathrm{MgO}(21.2\right.$ $\pm 0.6), \mathrm{Na}_{2} \mathrm{O}(11.8 \pm 0.6), \mathrm{Ga}_{2} \mathrm{O}_{3}(6.0 \pm 0.6) \mathrm{mol} \%$ ], the deposited $\mathrm{P} 40 \mathrm{PVD}$ coating $\left[\mathrm{P}_{2} \mathrm{O}_{5}\right.$ (40.5 \pm 0.3$), \mathrm{CaO}(15.5 \pm 0.2), \mathrm{MgO}(22.2 \pm 0.3), \mathrm{Na}_{2} \mathrm{O}(15.4 \pm 0.2), \mathrm{Ga}_{2} \mathrm{O}_{3}(6.4 \pm 0.1)$ mol\%] and P40PVD's melt-quenched equivalent, P40MQ [ $\mathrm{P}_{2} \mathrm{O}_{5}(40.4 \pm 0.1), \mathrm{CaO}(14.3$ $\pm 0.1), \mathrm{MgO}(23.0 \pm 0.1), \mathrm{Na}_{2} \mathrm{O}(15.5 \pm 0.2), \mathrm{Ga}_{2} \mathrm{O}_{3}(6.9 \pm 0.2)$ were calculated based on the EDX elemental results. A non-stoichiometric target-to-substrate transfer due to preferential sputtering phenomena was noticed leading to a reduction in $\mathrm{P}_{2} \mathrm{O}_{5}$ by 8.4 mol\% and an increase in $\mathrm{CaO}, \mathrm{MgO}, \mathrm{Na}_{2} \mathrm{O}$ and $\mathrm{Ga}_{2} \mathrm{O}_{3}$ by 3.4, 1.0, 3.4 and $0.4 \mathrm{~mol} \%$, respectively.
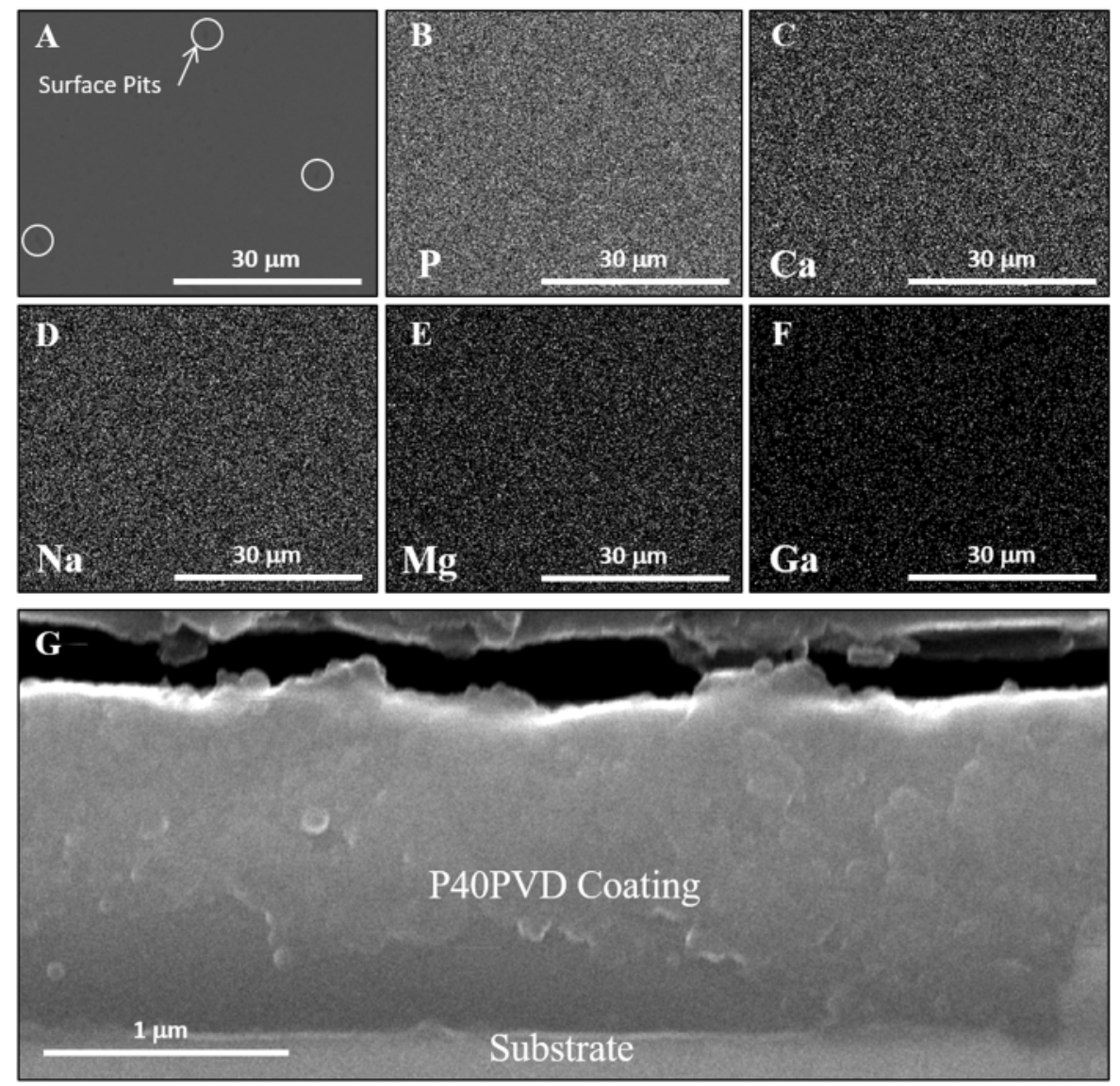

Figure 1: (A-F) Characteristic SEM surface image and corresponding EDX elemental mappings of P4OPVD. (G) FEG-SEM cross-sectional image of P4OPVD on cp-Ti substrate.

SEM revealed the presence of surface pits for P40PVD, whilst elemental EDX mapping showed homogenous distribution of all functional elements across the sample surface, without segregation (Figure 1). 


\subsection{Spectroscopic ellipsometry}

Spectroscopic ellipsometry (SE), measurements for coatings deposited onto Si (100) wafers from 3 independent batches, revealed an overall thickness of $1452 \pm 8 \mathrm{~nm}$ (and thus a deposition rate of $73 \pm 1 \mathrm{~nm} \mathrm{~h}^{-1}$ ) with a mean surface roughness of $8 \pm 1 \mathrm{~nm}$. Mean Cauchy coefficients, a, b and c, were obtained as 1.56, 0.0065 and 0.0001, respectively, and were incorporated into the Cauchy relationship to obtain the refractive index for the glass coating as shown in Figure $2 B$. The mean square error of the fit between the model and the acquired data was calculated as $28 \pm 1$.
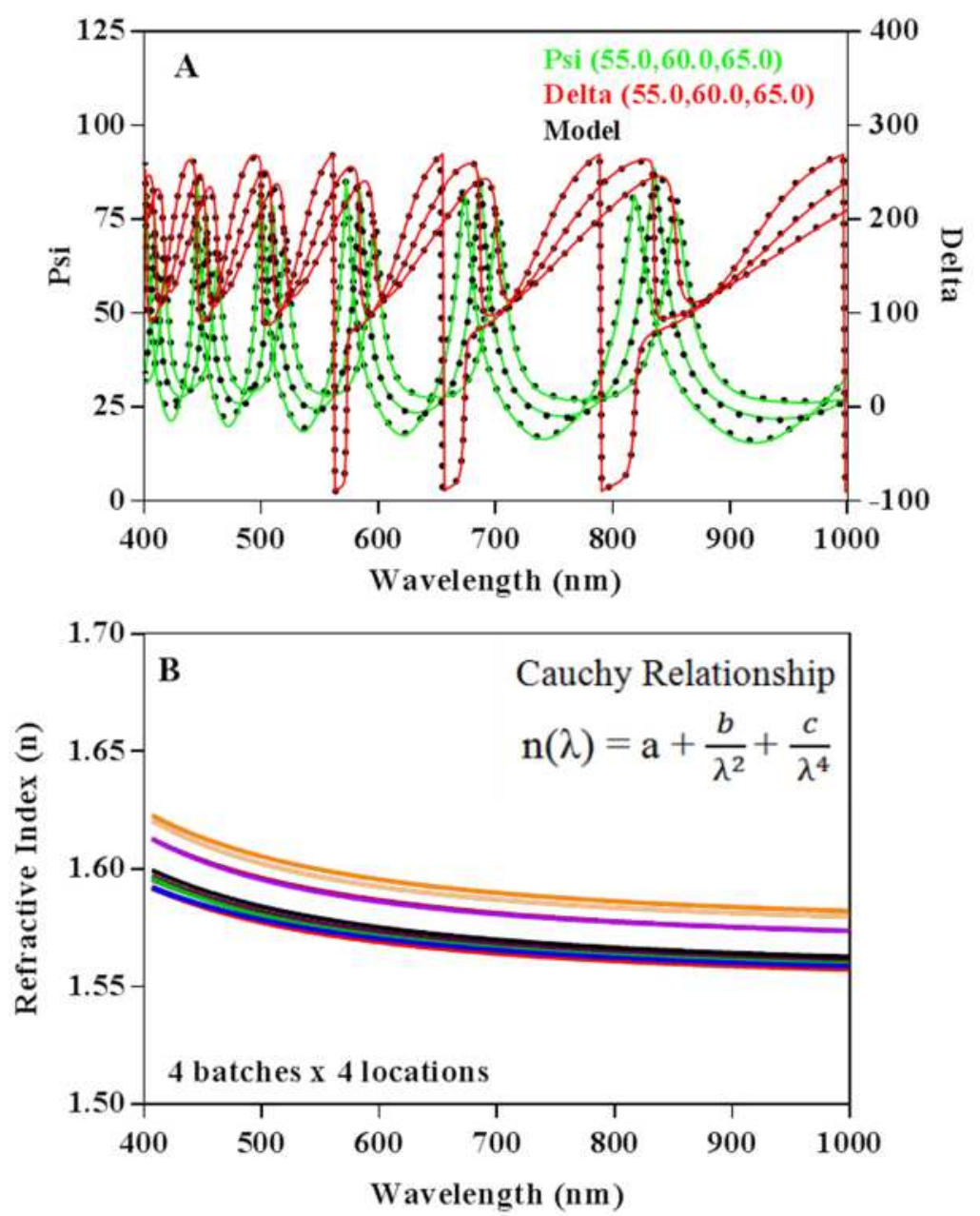

Figure 2: SE spectra of P4OPVD film on Si wafer. (A) Characteristic fit between the obtained measurement and the model from a single measurement. (B) Calculated refractive index based on the optical constants factored into the Cauchy relationship.

\subsection{Density by Helium Pycnometry and Micro Balance}

Melt quenched glass densities were measured by helium pycnometry for P51MQ and P40MQ were of $2.56 \pm 0.02$ and $2.70 \pm 0.01 \mathrm{~g} \mathrm{~cm}^{-3}$, respectively. P40PVD was redeposited over 3 independent batches onto cp-Ti discs $(n=8)$. The density was calculated as $3.47 \pm 0.09 \mathrm{~g} \mathrm{~cm}^{-3}$. 


\subsection{XRD}

Broad diffraction halos, centred at $2 \theta \approx 25^{\circ}$ and $\approx 28^{\circ}$, were identified for P51MQ and P40MQ respectively (Figure 3A), characteristic of an X-ray amorphous compound. In the case of P40PVD, the GIXRD pattern (Figure 3B) indicated the presence of a slender amorphous halo (typical of glassy structures) slightly shifted towards higher angles with respect to P51MQ. The only crystalline peaks appertain to the cp-Ti substrate (ICDD: 00044-1294).

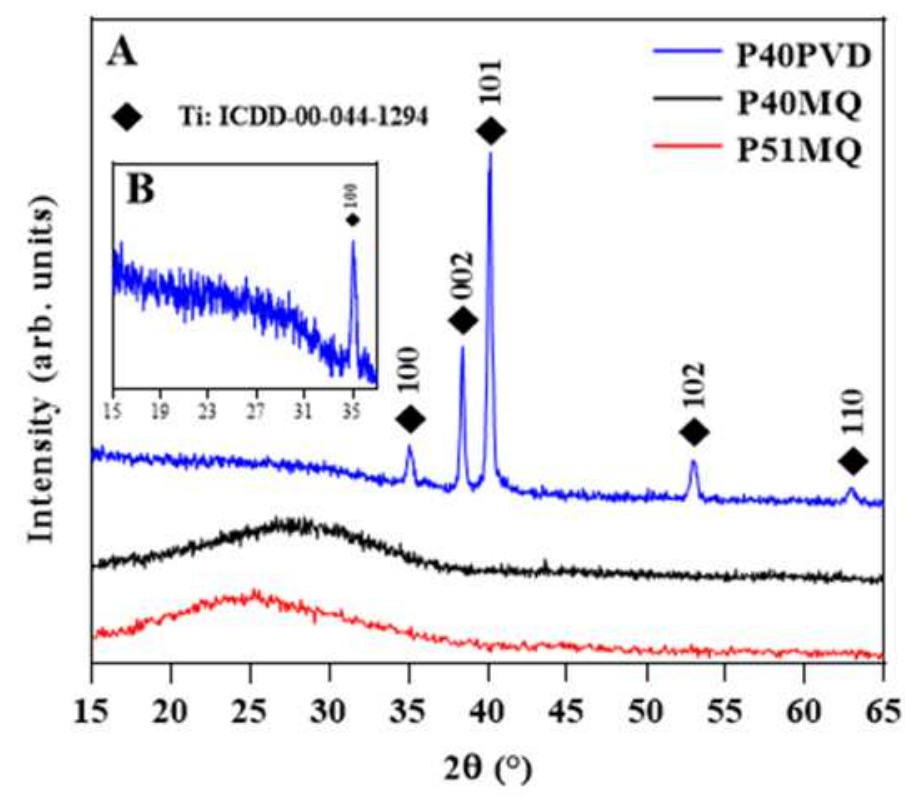

Figure 3: (A) XRD analysis of P4OPVD, P4OMQ and P51MQ. (B) Magnified amorphous halo observed for P4OPVD.

\section{$3.5^{31} P-N M R$}

The ${ }^{31} \mathrm{P}-\mathrm{NMR}$ spectra in Figure 4 showed chemical shifts associated with both $\mathrm{Q}^{1}$ and $\mathrm{Q}^{2}$ tetrahedral species of the $\mathrm{PO}_{4}{ }^{3-}$ unit. $\mathrm{P} 51 \mathrm{MQ}$ was formed as a quasicontinuous polyhedral chain consisting of $95: 5 \mathrm{Q}^{2}: \mathrm{Q}^{1}$ ratio which was likely due to the large network forming presence of $51 \mathrm{~mol} \% \mathrm{P}_{2} \mathrm{O}_{5}$ within the structure. Sputtering atomic transfer of P51MQ to the film (i.e., P40PVD) revealed a 61:32:8 $\mathrm{Q}^{2}: \mathrm{Q}^{1}: \mathrm{Q}^{0}$ ratio; thus, a considerable increase of $\mathrm{Q}^{1}$ content along with the emergence of $\mathrm{Q}^{0}$ orthophosphate species was recorded at the expense of $\mathrm{Q}^{2}$ species. The incorporation of additional $\mathrm{Q}^{1}$ structural units of either as chain terminating end groups or as isolated $\mathrm{P}_{2} \mathrm{O}_{7}{ }^{4-}$ pyrophosphates resulted in a strong network depolymerisation. The compositionally equivalent P40MQ was composed of 47:53 $\mathrm{Q}^{2}: \mathrm{Q}^{1}$. The depolymerisation of $\mathrm{P} 40$ structures as compared to 
P51 results from a reduction in the amount of phosphorous which functions as a network former.

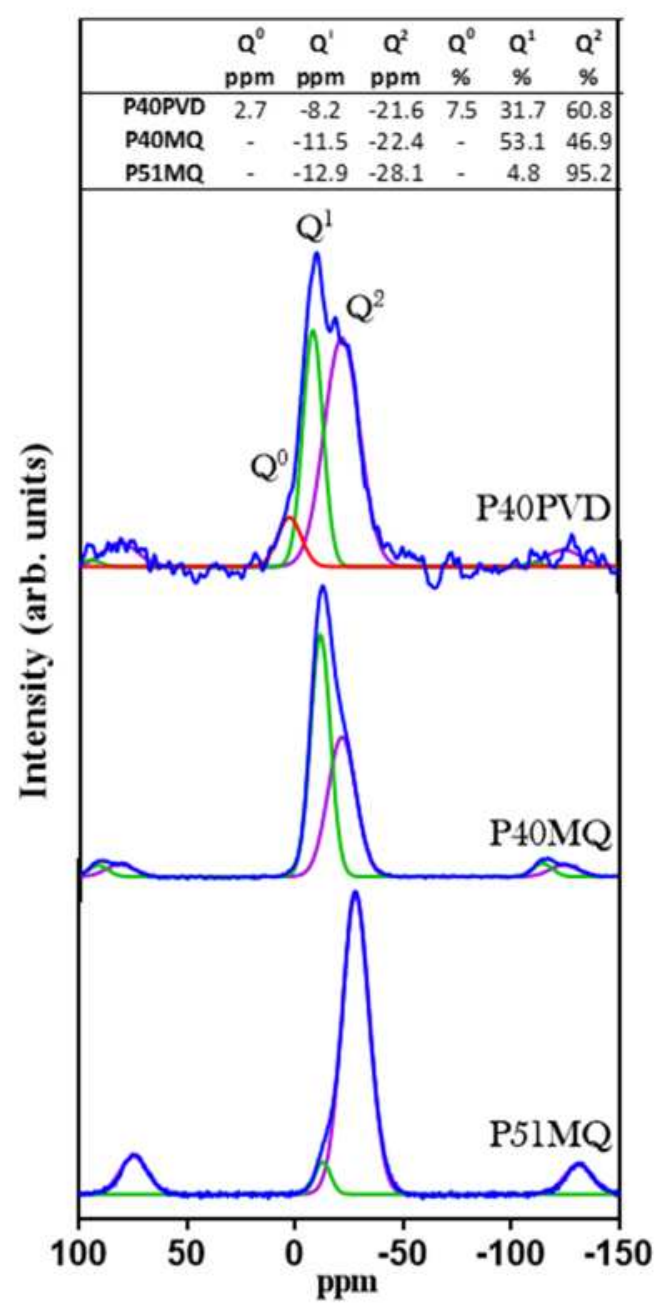

Figure 4: ${ }^{31} P-N M R$ of $P 51 M Q, P 40 M Q$ and P4OPVD with fits to determine the amount of the $Q^{n}$ tetrahedral species within each glass as an indication of structural polymerisation (network connectivity). Table inset represents the location of each chemical shift and the proportions of the $Q^{n}$ species.

\subsection{FTIR and micro-Raman spectroscopy}

For both PVD and MQ samples, FTIR spectroscopy revealed similar vibrational bands related to the structural phosphate tetrahedral groups at $739-748,903-908,988-1000$, 1094-1101 and 1260-1265 $\mathrm{cm}^{-1}$ (Figure 5A). Specifically, they are associated with following modes: symmetric stretching of the bridging oxygens in $\mathrm{Q}^{2}$ units $\left[v_{\mathrm{s}}(\mathrm{P}-\mathrm{O}-\mathrm{P})\right]$, asymmetric stretching of the bridging oxygens in $\mathrm{Q}^{2}$ units $\left[v_{\mathrm{as}}(\mathrm{P}-\mathrm{O}-\mathrm{P})\right]$, symmetric stretching of chain-terminating $\left(\mathrm{Q}^{1}\right)$ units $\left[\mathrm{v}_{\mathrm{s}}\left(\mathrm{PO}_{3}\right)^{2-}\right]$, asymmetric stretching of chainterminating $\mathrm{Q}^{1}$ units $\left[\mathrm{vas}_{\mathrm{as}}\left(\mathrm{PO}_{3}\right)^{2-}\right]$, and asymmetric stretching of the non-bridging oxygens atoms within the $\left(\mathrm{Q}^{2}\right)$ units $\left[\mathrm{v}_{\mathrm{as}}(\mathrm{O}-\mathrm{P}-\mathrm{O})\right]$, respectively. The peaks between 522 and 536 
$\mathrm{cm}^{-1}$ were at the lower spectral limit of the ATR diamond/ZnSe crystal window and may not be clearly defined, however are associated with $\mathrm{Q}^{0} \mathrm{PO}_{4}{ }^{3-}$ or $\mathrm{PO}^{-}$deformation modes [10, 37-40]. P40PVD and P40MQ showed a substantial increase of the absorption band at $1094-1101 \mathrm{~cm}^{-1}$, attributed to greater $\mathrm{Q}^{1}$ within $\mathrm{P} 40$ structures, which points towards a more depolymerized structure with respect to the P51MQ material and is attributed to the lower P content of the P40PVD and P40MQ, in good agreement with the NMR results (Figure 4). This is supported also by the simultaneous intensity reduction of the band positioned at $1265 \mathrm{~cm}^{-1}$, visible only as faint shoulder for P4OPVD $\left(1260 \mathrm{~cm}^{-1}\right)$, unveiling the overall decline in $\mathrm{Q}^{2}$ species. Comparison of P40PVD and P40MQ showed a shift of 5-7 $\mathrm{cm}^{-1}$ to higher vibrational frequencies for the bands at 748, 908, 995 and $1101 \mathrm{~cm}^{-1}$ as found in P40MQ. This has been attributed to greater packing density of MQ glasses as compared to the PVD glasses. A pronounced shoulder at $1180 \mathrm{~cm}^{-1}$ for P40MQ is associated with symmetric stretching of non-bridging oxygens atoms within the $\left(\mathrm{Q}^{2}\right)$ units $\left[v_{\text {as }}(\mathrm{O}-\mathrm{P}-\mathrm{O})\right]($ Figure $5 A)[40]$.

The prominent two distinct Raman bands of P51MQ, peaking at 712 and $1185 \mathrm{~cm}^{-1}$, are attributed to the symmetric stretching modes of $\mathrm{P}-\mathrm{O}-\mathrm{P}$ bridging oxygens and $\mathrm{O}-\mathrm{P}-\mathrm{O}$ non-bridging oxygens in $\mathrm{Q}^{2}$ phosphate units, respectively. The minor peaks at 351 and $1288 \mathrm{~cm}^{-1}$ are associated to the bending vibrations of $\mathrm{O}-\mathrm{P}-\mathrm{O}$ non-bridging oxygens and to the superimposed contributions of the asymmetric stretching of non-bridging oxygen in $\mathrm{Q}^{2}$ units and symmetric stretching of the terminal oxygen bonds $\left[\mathrm{v}_{\mathrm{s}}(\mathrm{P}=\mathrm{O})\right]$, respectively [40-42]. Raman shifts were observed for P40PVD at 329, 711, 950, 1043, 1148, 1230 $\mathrm{cm}^{-1}$. The supplemental emerging maxima, shoulder centred at $950 \mathrm{~cm}^{-1}$ and sharp peak positioned at $1043 \mathrm{~cm}^{-1}$ are attributed to symmetric stretching of the $\mathrm{O}-\mathrm{P}-\mathrm{O}$ non-bridging oxygens in $\mathrm{Q}^{0}$ and $\mathrm{Q}^{1}$ units, respectively [10, 39, 40, 43-45] (Figure 5B). The considerable increase in intensity $\left(329 \mathrm{~cm}^{-1}\right)$ or appearance $\left(1043 \mathrm{~cm}^{-1}\right)$ of specific bands, unveil the higher concentration of non-bridging oxygens bonds in the case of P40PVD, and thus its more disrupted network, in good agreement with FTIR assessments (Figure 5A). Comparison of the compositionally equivalent P40MQ and P40PVD shows a relative reduction in the peak located at $351 \mathrm{~cm}^{-1}$ suggesting a reduction of the nonbridging oxygen concentration for the former. The emergence of three distinct low intensity maxima, peaking in the $500-625 \mathrm{~cm}^{-1}$ region, has been attributed to the bending vibrations of the $\mathrm{P}-\mathrm{O}$ bonds and in chain $\mathrm{P}-\mathrm{O}-\mathrm{P}$ stretching vibrations. Also in agreement with the shift of the IR bands towards higher frequencies the shift in the Raman spectra from 711 to $739 \mathrm{~cm}^{-1}$ in P40MQ compared to P40PVD signifies a reduction in chain 
length and increased density. Finally, the increased relative intensity of the band positioned at $1148 \mathrm{~cm}^{-1}$ suggests an augmented concentration of the $\mathrm{Q}^{2}$ tetrahedral units (Figure 5B) [44, 45].
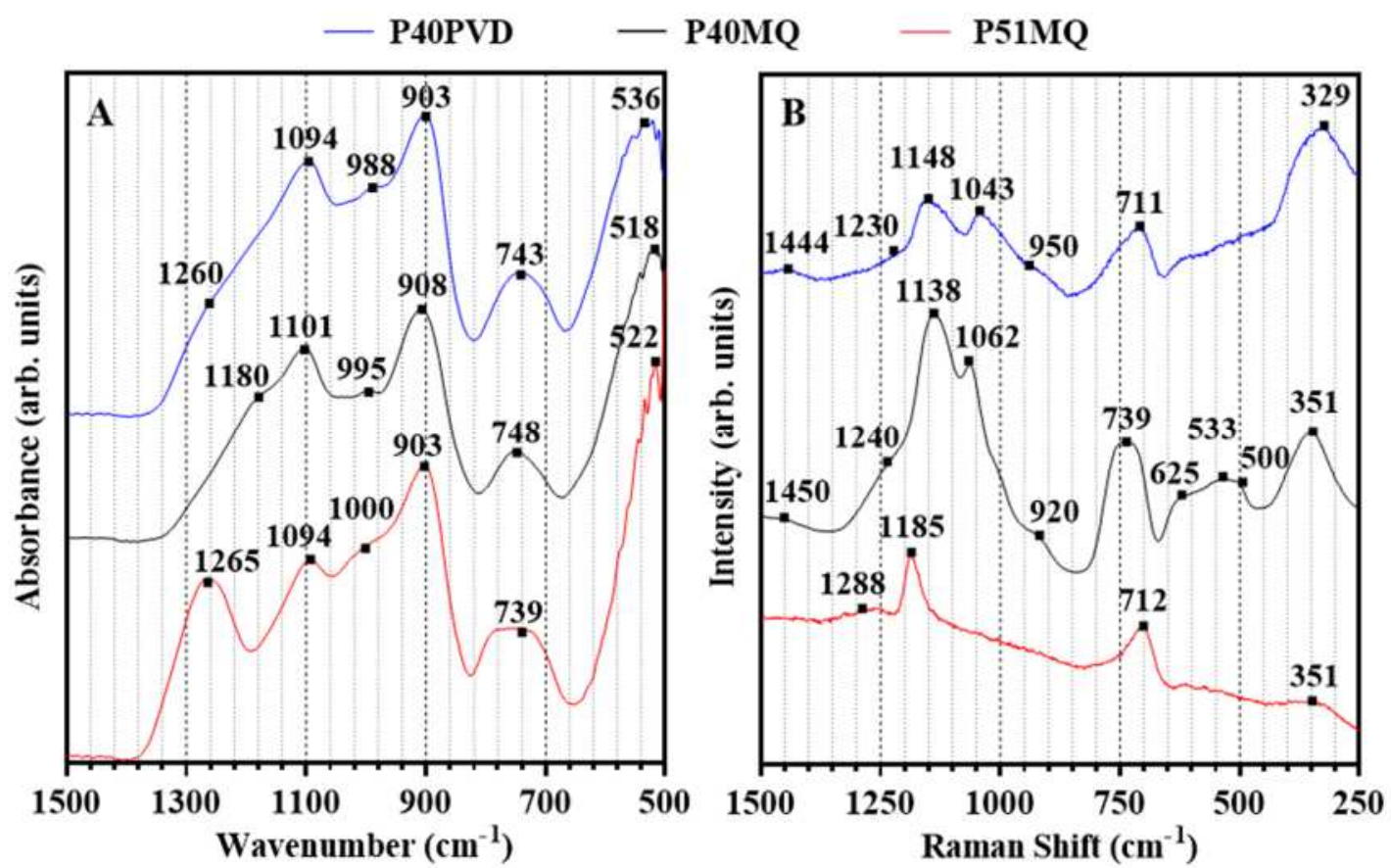

Figure 5: Comparative (A) FTIR, and (B) micro-Raman spectra of $P V D$ and $M Q P B G$ structures.

\subsection{AFM}

The arithmetic average of the roughness profile $\left(\mathrm{R}_{\mathrm{a}}\right)$ values of the cp-Ti substrate, P40PVD on cp-Ti, P40MQ, and P51MQ surfaces (used further for nano-indentation assays), inferred from AFM, were of $4.8 \pm 0.8 \mathrm{~nm}, 7.9 \pm 3.0 \mathrm{~nm}, 8.8 \pm 0.6 \mathrm{~nm}$, and $7.6 \pm$ $1.4 \mathrm{~nm}$, respectively. Representative AFM micrographs for cp-Ti and P40PVD are presented in Figure $6 A$ and $B$, respectively. Comparison of Figure $6 A$ and Figure $6 B$ showed visible pits uniformly dispersed across the entirety of P40PVD surface. The measured depths of 10 randomly chosen pits on the micrograph in Figure $6 B$ ranged from $\sim 8.0$ to $\sim 21.5 \mathrm{~nm}$. This depth penetration can be further visualised in the $90^{\circ}$ projected view. 


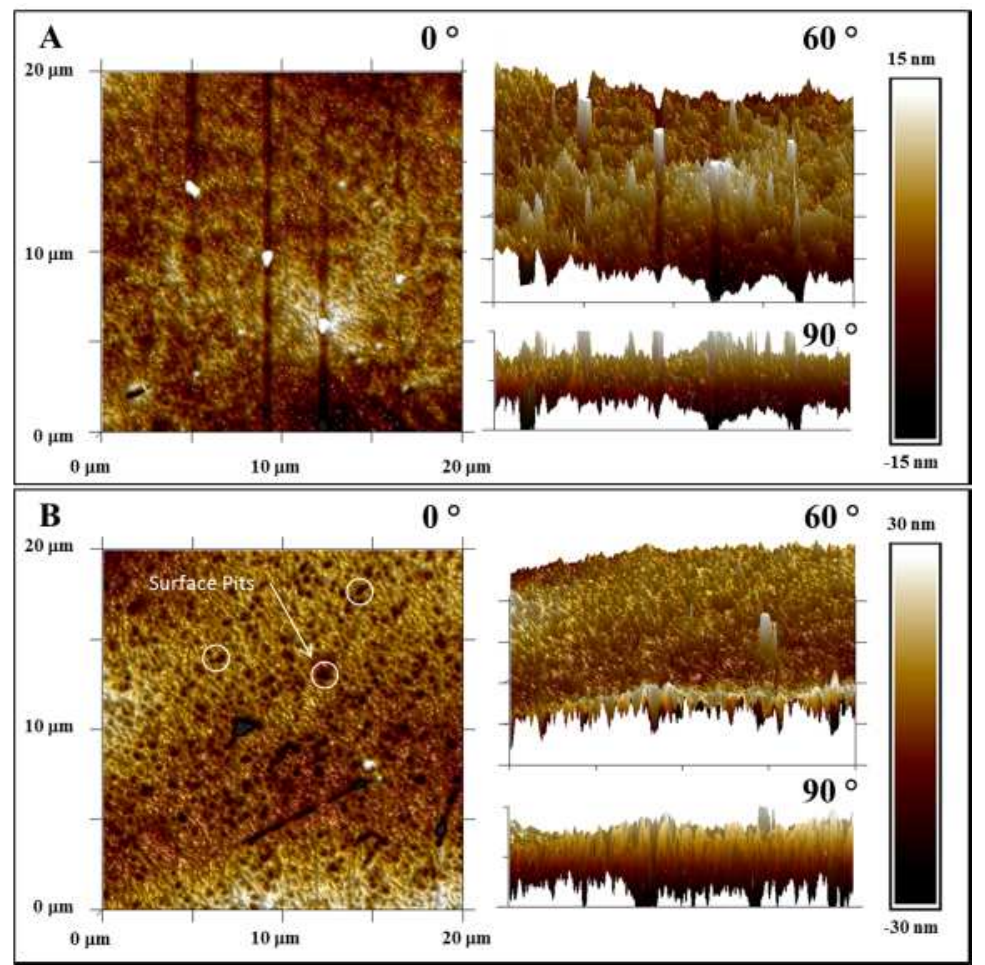

Figure 6: AFM surface and rotated images of (A) cp-Ti substrate and (B) P4OPVD coating on cp-Ti substrate. Surface pits at $0^{\circ}$ can be visualized throughout the surface of the sample, and can additionally be observed in the $90^{\circ}$ projected view.

\subsection{Nano-indentation}

Static indentations on P51MQ, P40MQ, P40PVD and cp-Ti were made at the central region, 10x10 arrays, over a $1 \mathrm{~mm}$ square area. P51MQ, P40MQ and P40PVD had reduced moduli $\left(\mathrm{E}_{\mathrm{r}}\right)$ and hardness $(\mathrm{H})$ values of $(71.7 \pm 4.2$ and $5.7 \pm 0.6 \mathrm{GPa}),(85.5 \pm$ 5.8 and $7.4 \pm 0.8 \mathrm{GPa}),(76.6 \pm 2.4$ and $4.7 \pm 0.2 \mathrm{GPa})$, respectively. The average and standard deviation values of cp-Ti reduced modulus were of $127.9 \pm 6.2 \mathrm{GPa}(\mathrm{n}=256)$. Normal (Gaussian) distributions for all four samples were observed (Figure 7). 

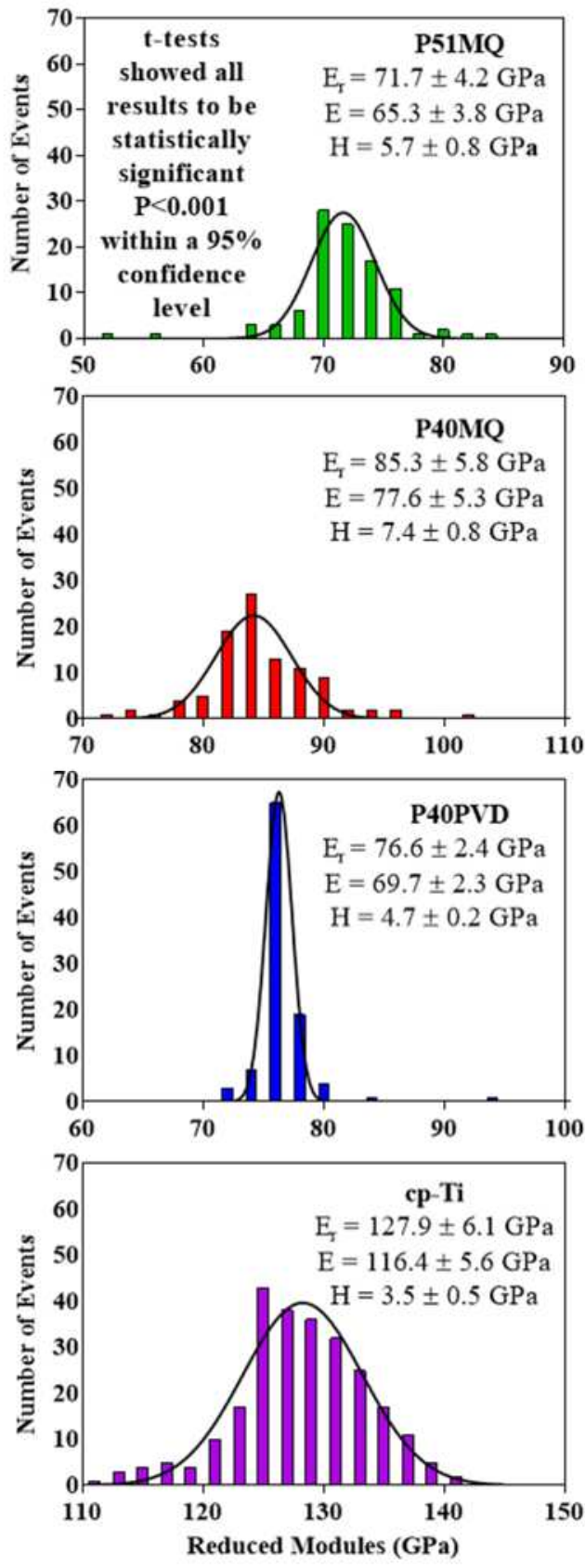

Figure 7: Reduced moduli distribution of static nano-indentation for all four samples, utilising a histogram unit bin width of 2 GPa. The tables inset contain the mean \pm standard deviation of the reduced modulus, elastic modulus and hardness. Elastic modulus was calculated based on a theoretical Poisson's Ratio of 0.3.

Load-displacement curves for each glass sample were presented in Figure $8 \mathrm{~A}$ and showed a consistent increase in displacement depth with loads up to $2.5 \mathrm{mN}$ followed by inelastic deformation. The elastic moduli (E) have been calculated and reported in Figure 7, using an average theoretical poisson's ratio of 0.3 for phosphate-based glasses as reported by Limbach et al. and Zysset et al [46, 47]. The three indices to infer elastic response, toughness and abrasive resistance, $\mathrm{H} / \mathrm{E}, \mathrm{H}^{3} / \mathrm{E}^{2}$ and $\mathrm{H} / \mathrm{E}^{2}$ respectively were calculated and 
compared in Figure 9 and showed that implant mechanical surface properties would be significantly improved by application of P40PVD on to cp-Ti.

For the reported modulus and hardness data, the nano-indentation load was optimised on the P40PVD such as to ensure the contact depth did not exceed $10 \%$ of the thickness of the film. However, to demonstrate that the cp-Ti substrate does not have an effect on the resulting modulus, a single indentation of $10 \mathrm{mN}$ was executed on the film. An AFM image of the surface before and after the indentation is shown in Figure $8 B$, along with a line profile of the deepest part of the residual indent. The recorded modulus for this indentation was $90.8 \mathrm{GPa}$, and has penetrated $300 \mathrm{~nm}$ into the $\sim 1452 \mathrm{~nm}$ thick film. Whereas the modulus for the film at indents less than $130 \mathrm{~nm}$ was $76.6 \pm 2.4 \mathrm{GPa}$.
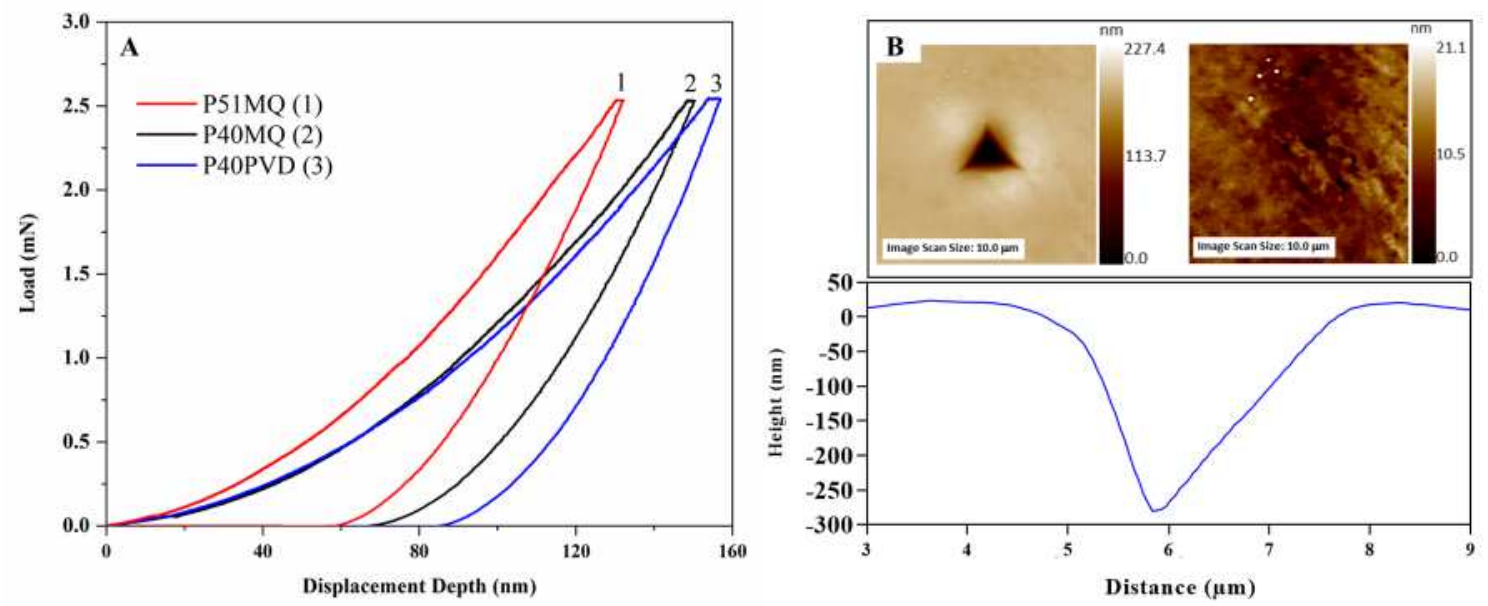

Figure 8: (A) Characteristic load displacement curves for P51MQ, P40MQ, and P4OPVD on cp-Ti. (B) AFM images of the surface of P4OPVD before and after an indentation at maximum load $(10 \mathrm{mN})$, with corresponding line profile showing the depth of the indentation. 

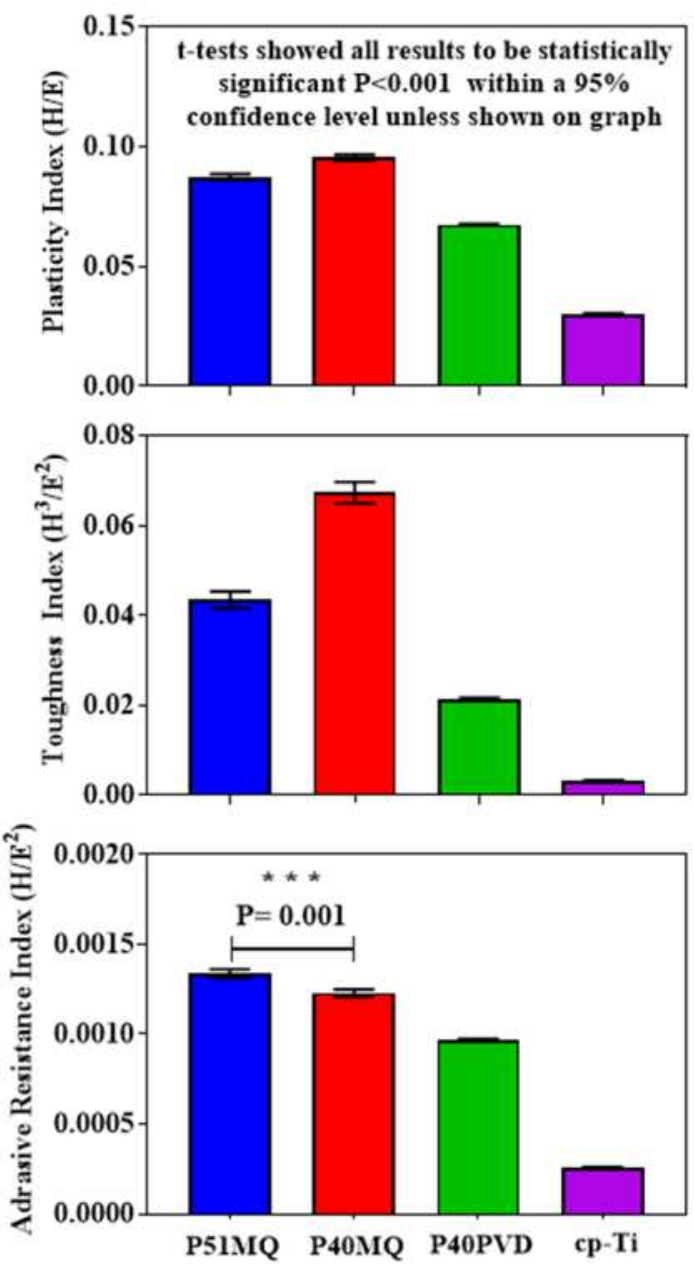

Figure 9: Ratios of hardness to elastic modules, which may be used to infer wear response by analysis of plasticity, toughness, and abrasive resistance of materials using nano-indentation results.

\section{Discussion}

Gallium was incorporated into the PBG P51MQ target structure and subsequently sputtered as P40PVD, onto medically applicable cp-Ti for future utilisation as an antimicrobial and osteogenic ion leaching coating. Quinternary PBG's are complex amorphous structures consisting of both ionic and covalent bonds within a polymerised oxide network. The primary aim of this study was to incorporate the known antimicrobial element (Gallium) [10] into a glass and to assess both elastic and hardness properties for future industrial relevance of magnetron sputtered orthopaedic coatings for future ionic release in vitro. The secondary aim was to explore and understand the structural, compositional and mechanical changes from the original preformed target (P51MQ) to the condensed layer (P40PVD). The compositionally equivalent melt-quenched glass (P40MQ) was manufactured and assessed to determine whether glass structural and 
mechanical properties were dictated by composition or by manufacturing route (or more directly, formation kinetics).

\section{Coating Thickness}

Spectroscopic Ellipsometry (SE), has emerged as a powerful technique for measuring single/multi-layered thicknesses and optical properties for films ranging from atomic layers to microns [48]. P40PVD was deposited as a coating onto cp-Ti to a thickness of $\approx 1452 \mathrm{~nm}$. Measurements over four independent batches and four locations demonstrated reproducibility of the sputtering process to a standard error of $\pm 0.01 \mu \mathrm{m}(\approx 0.5 \%$ of the total coating thickness) (Figure 2). According to Kirkpatrick et al. structural properties may be inferred based on the correlation between increasing density, increasing glass transition and lower thermal expansion with greater refractive index, resulting from shorter/stronger bonding of P-O forming oxide [49]. The SE modelling for P40PVD (Figure 2A) was limited to the transparent range between wavelengths of 400 and 1000 $\mathrm{nm}$ due to phonon absorption in the UV and infrared, effects caused by electron and atomic excitation as reported by Khor et al. for $\mathrm{Zn} / \mathrm{Mg}$ phosphate glasses with reported refractive indices at $632.8 \mathrm{~nm}$ ranging from $1.568-1.575 \mathrm{~nm}$ which increased with decreasing cross-linking density as $\mathrm{MgO}$ replaced $\mathrm{P}_{2} \mathrm{O}_{5}$ [50]. The refractive index found in the SE model here ranged from 1.570-1.610 which could suggest variability in structural polymerisation or density [50].

The complementary cross sectional FEG-SEM image (Figure $1 F$ ) supported the usage of $\mathrm{SE}$ as an indirect yet precise technique for thickness determination of PBG layers on mirror polished cp-Ti. The distinct features observed through the section of the coating may have been associated with the cross sectional pre-polishing process which resulted in smearing of the interface and section. Previous methodologies whereby coating directly onto thin borosilicate glass slides allowed for direct sectioning by cracking eliminated the necessity for post polishing. However, to obtain an exact representation of the coating deposited onto its intended substrate material the section may either be milled by Focused Ion Beam or embedded in resin and polished.

\section{Sample Composition and Coating Surface Features}

SEM surface micrographs showed distributed surface pits (Figure 1A), which were subsequently measured by AFM (Figure $6 B$ ) and found to be up to $\approx 21.5 \mathrm{~nm}$ in depth, limited to a maximum of $1.5 \%$ of the coating depth (Figure $6 B$ ). Pitting may have been caused by inadequate diffusion of the arriving atoms, atomic shadowing from the adatoms, or continuous etching by impinging atoms [28, 51, 52]. EDX micrographs 
recorded in the case of P40PVD coating (Figure $1 B-F$ ) showed a uniform distribution of all elements ( $\mathrm{P}, \mathrm{Ca}, \mathrm{Na}, \mathrm{Mg}$ and $\mathrm{Ga})$.

Compositional variations from P51MQ stoichiometry is produced as a result of the argon ion bombardment processes, characteristic of RFMS, unveiling a non-stoichiometric atomic transfer. This parent glass-to-sputtered coating incongruent atomic transfer has been termed "preferential sputtering" and is the result of the counteracting interatomic forces and the inherent bonding strength interactions of the glass structure itself. Stuart $e t$ $a l$. previously suggested that the variable energy required to break the respective oxide bonds within a glass was the dominant cause of preferential sputtering [29], whilst Gibbsian segregation due to ion bombardment allowed continuous alkali migration to the surface of the sputtered sample $[53,54]$. Furthermore, Stan et al. reported on additional momentum exchange interactions such as backscattering based on differential mass of sputtered atoms and background argon ions, relating to the mean free path during travel from target to substrate [55].

\section{Structural Analysis}

Glasses are formed by quenching, condensing or polymerising a substance from its molten, vapour or colloidal states with sufficient entropy to maintain its highly-disordered structure [56]. PBG's are bound together by $\mathrm{PO}_{4}{ }^{3-}$ tetrahedral units interconnected by network modifier ions or P-O-P bridging oxygens [6].

P51MQ and P40MQ were quenched from their molten states from $1200{ }^{\circ} \mathrm{C}$ to $450{ }^{\circ} \mathrm{C}$, below the anticipated glass transition $\left(\mathrm{T}_{\mathrm{g}}\right)$, freezing the internal structure with insufficient time to nucleate and arrange into crystallites. The high enthalpy/entropy state may lead to distributed residual stresses which could reduce mechanical integrity and increase dissolution rates; rectified through post-deposition annealing for stress relaxation [5]. During conventional quenching heat must dissipate through $\mathrm{mm} / \mathrm{cm}$ of liquid glass, cooling at $\approx 100-1000 \mathrm{~K} \mathrm{~s}^{-1}$. In contrast, P40PVD may be considered a hyper-quenched glass, where-by comparison, the $\approx 1452 \mu \mathrm{m}$ thick coating is grown from subsequent instantaneously condensed angstrom layers at a rate of $\left(\approx 12 \AA \mathrm{min}^{-1}\right)$. A study by Dabas et al. showed that by increasing quenching rates of lithium containing PBG the formation of structural $\left(\mathrm{Q}^{1}\right)$ pyrophosphate units could be supressed leading to a higher entropy structure, which vastly enhanced the intended electrical conductivity of the glass [57]. A similar reduction in $\mathrm{Q}^{1}$ and increase in $\mathrm{Q}^{0}$ and $\mathrm{Q}^{2}$ structural components was also shown during a comparison of three compositionally equivalent MQ and PVD condensed 
compositions (Figure 4) [28]. Singh et al. and Kearns et al. proposed that the enthalpy of condensing glassy materials could be controlled by maintaining the substrate temperature at $85 \%$ of the $\mathrm{T}_{\mathrm{g}}$, thereby allowing for in situ relaxation $[58,59]$.

GIXRD (Figure 3A) revealed a broad diffraction halo associated with the short range polyhedral structure $\left(\mathrm{PO}_{4}\right)$ of the amorphous glasses for both P51MQ and P40MQ. Similarly, rapid condensation of P40PVD led to its amorphous formation as demonstrated by the broad shoulder between $15-35^{\circ}(2 \theta)$ (Figure $3 B$ ). The visible diffraction peaks present in the $2 \theta$ region $35-65^{\circ}$ were attributed to $\mathrm{Ti}$ as impinging $\mathrm{X}$-rays penetrated the thin film down to the substrate.

${ }^{31} \mathrm{P}-\mathrm{NMR}$, IR and Raman spectroscopy showed a decrease in structural polymerisation, as the P51MQ target glass was vaporised and re-condensed on to the cp-Ti substrate to form the coating P40PVD. Furthermore, similar to previous studies, P40PVD was shown to have greater structural polymerisation and to contain $\mathrm{Q}^{0}$ orthophosphate units as compared to P40MQ [28]. The two distinct Raman shifts observed for P51MQ at 712 and $1185 \mathrm{~cm}^{-1}$ were associated with majority structural $\mathrm{Q}^{2}$ units (Figure $5 B$ ), as also shown by ${ }^{31} \mathrm{P}-\mathrm{NMR}$ which indicated a proportional $\mathrm{Q}^{2}: \mathrm{Q}^{1}$ structure of 95:5 (Figure 4). Following coating condensation to P40PVD, a substantial decrease in $\mathrm{Q}^{2}$ and increase in $\mathrm{Q}^{1}$, accompanied by the advent of $\mathrm{Q}^{0}$ tetrahedral units $\left(\mathrm{Q}^{2}: \mathrm{Q}^{1}: \mathrm{Q}^{0}\right.$ of $61: 32: 8$ was shown by ${ }^{31} \mathrm{P}-\mathrm{NMR}$ (Figure 4). This depolymerisation from the P51 to P40 compositions existed for both P40PVD and P40MQ and was complemented by the augmented intensity of the IR absorption band present between 1094-1101 $\mathrm{cm}^{-1}$ (Figure 5A) and by the Raman spectra from the appearance of bending vibrations of the $\mathrm{O}-\mathrm{P}-\mathrm{O}$ bonds at 329 or $351 \mathrm{~cm}^{-}$ ${ }^{1}$ and the shift at 1043 or $1062 \mathrm{~cm}^{-1}$ associated with O-P-O non-bridging oxygens of the $\mathrm{Q}^{0}$ and $\mathrm{Q}^{1}$ tetrahedral units in $\mathrm{P} 40 \mathrm{PVD}$ and $\mathrm{P} 40 \mathrm{MQ}$, respectively (Figure 5B). A comparison of P40 produced by PVD and MQ showed an increased structural polymerisation in $\mathrm{P} 40 \mathrm{PVD}$ as the ${ }^{31} \mathrm{P}-\mathrm{NMR}$ data showed a ratio $\mathrm{Q}^{2}: \mathrm{Q}^{1}: \mathrm{Q}^{0}$ tetrahedral units of 61:32:8 compared to $\mathrm{Q}^{2}: \mathrm{Q}^{1}$ of 47:53 in $\mathrm{P} 40 \mathrm{MQ}$ (Figure 4). In addition the greater relative intensity in $\mathrm{P} 40 \mathrm{MQ}$, of the Raman shifts positioned at $739 / 711 \mathrm{~cm}^{-1}$ and $1138 / 1148 \mathrm{~cm}^{-1}$ were attributed to symmetric stretching modes of the P-O-P bridging oxygens in the $\mathrm{Q}^{2}$ phosphate units (Figure $5 B$ ).

The observed increase in structural $\mathrm{Q}^{2}$ tetrahedral units was expected as P51MQ was reduced to $\mathrm{P} 40 \mathrm{PVD}$ in which the network forming $\mathrm{P}_{2} \mathrm{O}_{5}$ units varied from 51 to $40 \mathrm{~mol} \%$. The distinct absence of $\mathrm{Q}^{0}$ structural units was impart due to the higher proportion of $\mathrm{P}_{2} \mathrm{O}_{5}$, maintained above $40 \mathrm{~mol} \%$ in all glasses and the inclusion of the $\mathrm{Ga}_{2} \mathrm{O}_{3}$. As a 
trivalent oxide, $\mathrm{Ga}^{3+}$ has an ability to simultaneously cross-link and depolymerise the structure via ionic bonds leading to its greater durability in aqueous media. Furthermore $\mathrm{Ga}^{3+}$ may infiltrate the structural backbone as a network forming covalently bound unit to create hydration resistance bonds [10].

\section{Mechanical Properties}

Hip implants most commonly fail by wear induced osteolysis during which micro motion and spallation of the polyethylene particles from the acetabular cup shed into the surrounding tissue leading to phagocytosis $[32,60]$. HA coated implants are press fit into a hollowed out canal of the femur, which can cause coating spallation into the surroundings if abrasive resistance of the biofunctionalization material are insufficient $[61,62]$. A study by Bloebaum et al. found particles of HA up to $75 \mu \mathrm{m}$, and metal particles due to wear of the underlying metallic components embedded in the acetabular cup [61]. Failure at the $\mathrm{cp}-\mathrm{Ti} /$ coating interface may be perpetuated due to residual stresses within the layer during cooling, reported to increase with thickness [63]. Investigations of plasma sprayed HA thicknesses suggested that thinner layers have improved stability $[60,63,64]$. Bauer et al. suggested that coating thickness should remain under $100 \mu \mathrm{m}$ to prevent fatigue failures of the HA layer [60].

Although ceramic coatings of HA remain the industrial standard for orthopedic integration of medical implants by mimicking the human cortical bone, the next generation of PVD glasses may promote osteogenic stimulation and inhibit biofilm formation by releasing therapeutic and antimicrobial ions within the localized environment. In current and future cases of ceramics or glasses respectively, wear particles may be produced between any two contact surfaces under relative low micromotions. Coating failures occur by abrasive or interfacial detachment/cohesive failures from lateral forces and have therefore been assessed here for P40PVD on cp-Ti by nanoindentation. Whilst abrasive failure is likely, the FDA regulatory standard for testing orthopedic medical coatings relies solely on tensile pull-off testing to determine the force necessary to detach the film from its substrate. The excellent pull-off performance (>75 $\mathrm{MPa}$, limited by the strength of the epoxy used) of a similar coating composition containing $\mathrm{P}_{2} \mathrm{O}_{5}-40, \mathrm{Na}_{2} \mathrm{O}-16, \mathrm{CaO}-16, \mathrm{MgO}-24$, and $\mathrm{Fe}_{2} \mathrm{O}_{3}-4$ mol\% was previously demonstrated elsewhere, therefore only elastic properties were investigated here [5]. Nano-indentation probes the elastic properties of the glass surface providing an indication of its ability to withstand abrasive failures during surgical implantation and in vivo 
functioning. The potential to withstand plastic deformation through relative increases in properties such as hardness, and surface morphology of the abrading surface will alleviate abrasive failures [65].

The nano-mechanical properties of P51MQ and P40MQ were examined to determine if P40PVD on cp-Ti varied from its parent glass and if PVD structures acted mechanically similar to conventionally quenched glasses. Nano-indentation of cp-Ti (Figure 7) revealed an elastic modulus and hardness for cp-Ti of 116.4 and $3.5 \mathrm{GPa}$, respectively, consistent with bulk elastic modulus measurements reported by long et al of $105 \mathrm{GPa}$ [66].

Comparison of the melt-quenched composition (P51MQ vs. P40MQ) showed an increase in hardness and elastic modulus ( $\mathrm{H}=5.7$ vs. $7.4 \mathrm{GPa}$; $\mathrm{E}=65.3$ vs. $77.6 \mathrm{GPa})$. Contrary to this finding, many sources suggest that the increased polymerisation as shown by ${ }^{31} \mathrm{P}$ NMR (Figure 4) and reduction in network modifier content often creates deformation resistant structures. Hardness and elastic modulus values similarly matched those found by Limbach et al. for mixed fluoride phosphate glasses which ranged from $(\mathrm{H}=4.5$ to 6.3 $\mathrm{GPa}$; $\mathrm{E}=54.8$ to $92.5 \mathrm{GPa}$ ), increasing with fluoride inclusion up to $30 \mathrm{~mol} \%$ and decreasing thereafter until complete removal of phosphorous. The subsequent drop-off in elasticity was attributed to simultaneous inclusion of cross-linking $\mathrm{Al}^{3+}$ as $\mathrm{AlF}_{3}$ replaced $\mathrm{Sr}\left(\mathrm{PO}_{2}\right)_{2}[47]$.

Salama et al. suggested that $\mathrm{P}_{-} \mathrm{O}^{-}$and $\mathrm{P}=\mathrm{O}$ non-bridging oxygens, which were prevalent in less polymerised glasses, such as P40MQ, are locations susceptible to deformation due to unconstrained lateral motion within the structure [67]. This was further described by Limbach et al. as the ability to undergo shear flow in ionically bound cross-linkers [47]. However, this postulation cannot explain the contrasting increase in hardness following the depolymerisation of the network in P40MQ through the increased inclusion of network modifiers such as $\mathrm{Na}^{+}, \mathrm{Ca}^{2+}$ and $\mathrm{Ga}^{3+}$.

P40MQ and P40PVD revealed hardness values of 7.4 and $4.7 \mathrm{GPa}$, respectively. As shown by ${ }^{31} \mathrm{P}-\mathrm{NMR}, \mathrm{P} 40 \mathrm{PVD}$ contained a greater proportion of $\mathrm{Q}^{2}$ structural species and the presence of $\mathrm{Q}^{0}$ tetrahedral within its structure (Figure 4). This finding also contradicted the theorised suggestion that polymerisation was the primary factor leading to indentation resistance. Helium pycnometry measurements of P51MQ and P40MQ revealed respective densities of 2.56 and $2.70 \mathrm{~g} \mathrm{~cm}^{-3}$, whilst micro balance measurements of P40PVD revealed the highest density of $3.47 \mathrm{~g} \mathrm{~cm}^{-3}$. The higher density of P40MQ compared to P51MQ may have led to its superior mechanical properties. Hermansen et 
al. also reported that the bulk modulus in silicate glass structures increased with increasing density, showing that a glasses ability to undergo plastic deformation prior to catastrophic crack propagation was structure dependent and indirectly related to composition [68]. Felfel et al. measured the elastic properties $\mathrm{P}_{2} \mathrm{O}_{5}-50$ compared with $\mathrm{P}_{2} \mathrm{O}_{5}-40$ mol\% phosphate glasses finding elastic moduli of 51.5 and $62 \mathrm{GPa}$. They attributed the higher modulus as found here for the less polymerized glass to shorter chains and high packing density with the prevalence of $\mathrm{Q}^{1}: \mathrm{Q}^{2}$ structures of 56:44 [69]. Parsons et al. compared a $\mathrm{P}_{2} \mathrm{O}_{5}-50$ glass to a $\mathrm{P}_{2} \mathrm{O}_{5}-40$ mol\% glass composition, structurally similar to P40MQ and P40PVD with substitution of $\mathrm{Fe}^{3+}$ for $\mathrm{Ga}^{3+}\left(40-\mathrm{P}_{2} \mathrm{O}_{5}\right.$, 24- $\mathrm{MgO}, 16-\mathrm{CaO}, 16-\mathrm{Na}_{2} \mathrm{O} 4-\mathrm{Fe}_{2} \mathrm{O}_{3} \mathrm{~mol} \%$ ) by tensile failure and showed respective tensile moduli of 62 and $85 \mathrm{GPa}$ respectively [70].

Makishima and Mackenzie developed a simplified model to quantify elastic properties of silicate glasses based on composition, suggesting that elasticity was attributed to lower atomic packing density, lower volume and lower bond dissociation energies [71]. Sharmin et al. measured tensile modulus of nine compositions from $\mathrm{P}_{2} \mathrm{O}_{5}-40, \mathrm{P}_{2} \mathrm{O}_{5}-\mathrm{P} 45$ and $\mathrm{P}_{2} \mathrm{O}_{5}-50$ glasses which contained either 0,5 or $10 \mathrm{~mol} \mathrm{~B}_{2} \mathrm{O}_{3}$ which showed that the tensile modules increased and density decreased with $\mathrm{B}_{2} \mathrm{O}_{3}$ cross linking content [72].

Neither increased density $\left(3.47 \mathrm{~g} \mathrm{~cm}^{-3}\right)$ nor increased polymerization could explain the lower elastic response of P40PVD as compared to P40MQ. The variabilities between bulk and thin-film mechanical properties are widely documented and partly attributed to the mismatch in thermal expansion between the substrate and the condensed PVD layer. The larger contraction of P40PVD relative to the cp-Ti substrate upon cooling, would have formed tensile residual stresses within the glass coating, resulting in the observed reduction in mechanical integrity $[73,74]$.

The potential for Insitu structural relaxation by atomic diffusion, associated with sputtering, compared with melt-quenching may have contributed to the observed increase in density to $3.47 \mathrm{~g} \mathrm{~cm}^{-3}$ 67. PVD provides a means to condense glasses below their $\mathrm{T}_{\mathrm{g}}$, enabling them to surpass the kinetic barriers associated with conventional quenching [58]. Low enthalpy states with densified structures, characteristic of ultra-stable glasses may be attained due to the PVD process aiding prolonged molecular mobility. Multiple authors have suggested optimal relaxation occurs at the theoretical Kauzmann temperature, suggested by Singh et al. to be $85 \%$ of the $\mathrm{T}_{\mathrm{g}}[58,59,75,76]$. Furthermore, as described by Detor et al, densification in growing sputtered films has been attributed to atomic peening-like behaviour when high energy incoming particles continuously impact the 
deposited surface, leading to localised heating, material diffusion and interstitial penetration of atoms into the structure [77].

To highlight the relevance of P40PVD for its intended application as a biomedical coating, the hardness and elastic modulus found for P40PVD of 4.7 and $69.7 \mathrm{GPa}$ respectively, should be compared to the nano-indentation elastic response of the cortical bone surface of commercially applicable HA coating layers. Hardness and elasticity of (1.5-5/60-100 GPa) [78], (3.4-5.2/122-155 GPa) [79], (0.2-0.8/19.1 $\pm 5.4 \mathrm{GPa})$ [46], have been reported for plasma sprayed HA, magnetron sputtered HA films and cortical bone of the femur for patients aged $75.3 \pm 11.7$ years [46]. Park et al. reported ranges for elasticity and hardness of (84.4-91.1/4.0-4.0 GPa) for dental enamel in patients aged 1830 and $\geq 55$. Kinney et al. showed average values of $(29.8 \pm 8.9 \mathrm{GPa}) /(2.44 \pm 0.14 \mathrm{GPa})$ respectively for peritubular dentine and $(21.1 \pm 1.2 \mathrm{GPa}) /(0.51 \pm 0.02 \mathrm{GPa})$ respectively for intertubular dentine [80]. Various locations of the mandible were reported by Seong et al. as ranging from $(12.0-22.0 \mathrm{GPa})$ and $(0.22-0.67 \mathrm{GPa})$ to show that the mechanical properties obtained for P40PVD superseded the mechanical properties found at the dentine/mandible interface [80, 81].

Implant surfaces are likely to suffer from abrasive or plastic deformation during implantation or in in vivo micro motion [31,32]. As such, relationships between samples were inferred by assessment of plasticity $(\mathrm{H} / \mathrm{E})$, toughness $\left(\mathrm{H}^{3} / \mathrm{E}^{2}\right)$ and abrasive resistance $\left(\mathrm{H} / \mathrm{E}^{2}\right)$ indices as presented in Figure 9 [34, 82]. The application of P40PVD onto cp-Ti led to significant improvements in all inferred mechanical properties suggesting that PBG coatings may be suitable candidates to improve abrasive and wear resistance of dental and orthopaedic implants. The results found here show that the mechanical properties of P40PVD are within the range of plasma sprayed coatings whilst vastly superseding that of cortical bone and would therefore be deemed substantially equivalent for future utilisation as ion leaching antimicrobial and osteogenic coatings.

\section{Conclusions}

The variations in compositional, structural and nano-indentation elastic properties of the P51MQ target, the P40PVD as deposited coating and a compositionally equivalent P40MQ melt-quenched glass were assessed for future processing of PBG thin films as orthopedic and antimicrobial implant surfaces. The P51MQ target composition, $\mathrm{P}_{2} \mathrm{O}_{5}-$ 48.9, $\mathrm{CaO}-12.1, \mathrm{MgO}-21.2, \mathrm{Na}_{2} \mathrm{O}-11.8, \mathrm{Ga}_{2} \mathrm{O}_{3}-6.0 \mathrm{~mol} \%$ was formed of 5:95 $\mathrm{Q}^{1}: \mathrm{Q}^{2}$ structural species and was transferred onto the commercially pure titanium substrate as 
P40PVD, $\mathrm{P}_{2} \mathrm{O}_{5}-40.5, \mathrm{CaO}-5.5, \mathrm{MgO}-22.2, \mathrm{Na}_{2} \mathrm{O}-15.4, \mathrm{Ga}_{2} \mathrm{O}_{3}-6.4 \mathrm{~mol} \%$ with 8:32:61 $\mathrm{Q}^{0}: \mathrm{Q}^{1}: \mathrm{Q}^{2}$ structural species. Nano-indentation revealed elastic moduli $(65.3,69.7,77.6$ $\mathrm{GPa}$ ) and hardness values (5.7, 4.7, 7.4 GPa) for P51MQ, P40PVD and P40MQ, respectively, suggesting that the increase in density from 2.56 to $2.70 \mathrm{~g} \mathrm{~cm}^{-3}$ in meltquenched compositions led to improved mechanical properties. Whilst P40PVD had a densified structure of $3.47 \mathrm{~g} \mathrm{~cm}^{-3}$, attributed to enhanced atomic diffusion and atomic peening, as compared to $\mathrm{P} 40 \mathrm{MQ}$, its lower mechanical properties were ascribed to thermally induced residual stresses during cooling, commonly reported from the thermal expansion mismatch between coating and substrate materials.

\section{Acknowledgements}

This work was supported by the Engineering and Physical Sciences Research Council [grant numbers EP/K029592/1 and EP/M027333/1]; and the Centre for Innovative Manufacturing in Medical Devices (MeDe Innovation).

We acknowledge funding from the healthcare technologies research priority area at the University of Nottingham. The Nanoscale and Microscale Research Centre (NMRC), University of Nottingham for Access to Raman and Scanning Electron Microscopy. G.E.S. and A.C.P. are grateful for the financial support of the Romanian National Authority for Scientific Research and Innovation, CNCS-UEFISCDI, in the framework of project PN-II-RU-TE-2014-4-0180 (contract no. 73/2015).

\section{Data Availability}

The raw data used within this manuscript to produce all figures can be obtained by contacting the corresponding author Bryan W. Stuart.

\section{References}

1. Ahmed, I., et al., Composites for Bone Repair: Phosphate glass fibre reinforced PLA with varying fibre architecture. J Mater Sci Mater Med, 2011. 22(8): p. 1825-34.

2. Bunker, B.C., G.W. Arnold, and J.A. Wilder, Phosphate Glass Dissolution In Aqueous Solution. Journal of Non-Crystalline Solids, 1984. 64(3): p. 291-316.

3. Hench, L.L., Chronology of bioactive glass development and clinical applications. New Journal of Glass and Ceramics, 2013. 3(2): p. 67-73.

4. Stuart, B.W., et al., Degradation and Characterization of Resorbable Phosphate-Based Glass Thin-Film Coatings Applied by Radio-Frequency Magnetron Sputtering. ACS applied materials \& interfaces, 2015. 7(49): p. 27362-27372.

5. Stuart, B.W., et al., Mechanical, structural and dissolution properties of heat treated thin-film phosphate based glasses. Applied Surface Science, 2017. 416: p. 605-617. 
6. Knowles, J.C., Phosphate based glasses for biomedical applications. Journal of Materials Chemistry, 2003. 13(10): p. 2395-2401.

7. Neel, E.A., et al., Effect of iron on the surface, degradation and ion release properties of phosphate-based glass fibres. Acta Biomaterialia, 2005. 1(5): p. 553-563.

8. Kiani, A., et al., Titanium-containing bioactive phosphate glasses. Philos Trans A Math Phys Eng Sci, 2012. 370(1963): p. 1352-75.

9. Hoppe, A., N.S. Guldal, and A.R. Boccaccini, A review of the biological response to ionic dissolution products from bioactive glasses and glass-ceramics. Biomaterials, 2011. 32(11): p. 2757-74.

10. Valappil, S.P., et al., Antimicrobial gallium-doped phosphate-based glasses. Advanced Functional Materials, 2008. 18(5): p. 732-741.

11. Neel, E.A., et al., Characterisation of antibacterial copper releasing degradable phosphate glass fibres. Biomaterials, 2005. 26(15): p. 2247-54.

12. Ahmed, I., et al., Antimicrobial effect of silver-doped phosphate-based glasses. J Biomed Mater Res A, 2006. 79(3): p. 618-26.

13. Kaneko, Y., et al., The transition metal gallium disrupts Pseudomonas aeruginosa iron metabolism and has antimicrobial and antibiofilm activity. The Journal of Clinical Investigation, 2007. 117(4): p. 877-888.

14. Weber, K.A., L.A. Achenbach, and J.D. Coates, Microorganisms pumping iron: anaerobic microbial iron oxidation and reduction. Nature Reviews Microbiology, 2006. 4(10): p. 752-764.

15. Stan, G.E., et al., On the bioactivity of adherent bioglass thin films synthesized by magnetron sputtering techniques. Thin Solid Films, 2010. 518(21): p. 5955-5964.

16. Cattini, A., et al., Microstructural design of functionally graded coatings composed of suspension plasma sprayed hydroxyapatite and bioactive glass. Journal of Biomedical Materials Research Part B: Applied Biomaterials, 2014. 102(3): p. 551-560.

17. Cattini, A., et al., Suspension plasma spraying of optimised functionally graded coatings of bioactive glass/hydroxyapatite. Surface and Coatings Technology, 2013. 236: p. 118-126.

18. Rau, J., et al., Bioactive glass-ceramic coatings prepared by pulsed laser deposition from RKKP targets (sol-gel vs melt-processing route). Materials Research Bulletin, 2012. 47(5): p. 1130-1137.

19. Duta, L., et al., Ultra high molecular weight polyethylene acetabular cups functionalized with bioactive glass coatings synthesized by pulsed laser deposition. Rom. Rep. Phys, 2014. 66: p. 788-800.

20. Surmenev, R.A., A review of plasma-assisted methods for calcium phosphatebased coatings fabrication. Surface and Coatings Technology, 2012. 206(8): p. 2035-2056.

21. Popa, A., et al., Superior biofunctionality of dental implant fixtures uniformly coated with durable bioglass films by magnetron sputtering. Journal of the mechanical behavior of biomedical materials, 2015. 51: p. 313-327.

22. ISO, ISO 13779-2:2008: Implants for surgery -- Hydroxyapatite -- Part 2: Coatings of hydroxyapatite. 2008.

23. Callahan, T.J., J.B. Gantenberg, and B.E. Sand, Calcium phosphate (Ca-P coating) draft guidance for preparation of food and drug administration (FDA) 
sumbissions for orthopaedic and dental endosseuous implants A.S. 1196, Editor. 1994, American Society for Testing and Materials: Philadelphia.

24. Stan, G.E., et al., Strong bonding between sputtered bioglass-ceramic films and Ti-substrate implants induced by atomic inter-diffusion post-deposition heattreatments. Applied Surface Science, 2013. 280: p. 530-538.

25. Dowling, D., et al., Deposition of anti-bacterial silver coatings on polymeric substrates. Thin Solid Films, 2001. 398: p. 602-606.

26. Wolke, J.G., et al., Study of the surface characteristics of magnetron-sputter calcium phosphate coatings. J Biomed Mater Res, 1994. 28(12): p. 1477-1484.

27. Hasan, M.S., et al., Material Characterisation and Cytocompatibility Assessment of Quinternary Phosphate Glasses. Journal of Materials Science Materials in Medicine, 2012. 23(10): p. 2531-2541.

28. Stuart, B.W., et al., Insights into structural characterisation and thermal properties of compositionally equivalent vapour-condensed and meltquenched glasses. Materials \& Design, 2016. 111: p. 174-184.

29. Stuart, B., et al., Preferential sputtering in phosphate glass systems for the processing of bioactive coatings. Thin Solid Films, 2015. 589: p. 534-542.

30. Popa, A., et al., Nanomechanical characterization of bioglass films synthesized by magnetron sputtering. Thin Solid Films, 2014. 51: p. 313-327.

31. Amstutz, H.C., et al., Mechanism and clinical significance of wear debrisinduced osteolysis. Clin Orthop Relat Res, 1992(276): p. 7-18.

32. Abu-Amer, Y., I. Darwech, and J.C. Clohisy, Aseptic loosening of total joint replacements: mechanisms underlying osteolysis and potential therapies. Arthritis Res Ther, 2007. 9 Suppl 1: p. S6.

33. Schuh, C.A., Nanoindentation studies of materials. Materials Today, 2006. 9(5): p. 32-40.

34. Leyland, A. and A. Matthews, On the significance of the H/E ratio in wear control: a nanocomposite coating approach to optimised tribological behaviour. Wear, 2000. 246(1): p. 1-11.

35. Oliver, W.C. and G.M. Pharr, Measurement of hardness and elastic modulus by instrumented indentation: Advances in understanding and refinements to methodology. Journal of Materials Research, 2004. 19(01): p. 3-20.

36. Hay, J., P. Agee, and E. Herbert, Continuous stiffness measurement during instrumented indentation testing. Experimental Techniques, 2010. 34(3): p. 86-94.

37. Shih, P.Y., S.W. Yung, and T.S. Chin, FTIR and XPS Studies of P2O5-Na2O-CuO Glasses. Journal of Non-Crystalline Solids, 1999. 244(2-3): p. 211-222.

38. Al Qaysi, M., et al., Strontium-and calcium-containing, titanium-stabilised phosphate-based glasses with prolonged degradation for orthopaedic tissue engineering. Journal of Biomaterials Applications, 2015: p. 0885328215588898.

39. Velli, L., et al., Structural investigation of metaphosphate glasses. Physics and Chemistry of Glasses, 2005. 46(2): p. 178-181.

40. Kiani, A., et al., Structural characterization and physical properties of $\mathrm{P}_{2} \mathrm{O}_{5}-$ $\mathrm{CaO}-\mathrm{Na}_{2} \mathrm{O}-\mathrm{TiO}_{2}$ glasses by Fourier transform infrared, Raman and solid-state magic angle spinning nuclear magnetic resonance spectroscopies. Acta Biomaterialia, 2012. 8(1): p. 333-340.

41. Le Saout, G., et al., Raman and infrared study of (PbO) x (P205)(1-x) glasses. Journal of Raman Spectroscopy, 2002. 33(9): p. 740-746. 
42. Yadav, A.K. and P. Singh, A review of the structures of oxide glasses by Raman spectroscopy. RSC Advances, 2015. 5(83): p. 67583-67609.

43. Moguš-Milanković, A., et al., Structure of sodium phosphate glasses containing $\mathrm{Al}_{2} \mathrm{O}_{3}$ and/or $\mathrm{Fe}_{2} \mathrm{O}_{3}$. Part I. Journal of Non-Crystalline Solids, 2001. 289(1): p. 204-213.

44. Koo, J., B.-S. Bae, and H.-K. Na, Raman spectroscopy of copper phosphate glasses. Journal of Non-Crystalline Solids, 1997. 212(2): p. 173-179.

45. Pemberton, J.E., et al., Raman spectroscopy of calcium phosphate glasses with varying calcium oxide modifier concentrations. Chemistry of Materials, 1991. 3(1): p. 195-200.

46. Zysset, P.K., et al., Elastic modulus and hardness of cortical and trabecular bone lamellae measured by nanoindentation in the human femur. Journal of biomechanics, 1999. 32(10): p. 1005-1012.

47. Limbach, R., et al., Elasticity, deformation and fracture of mixed fluoridephosphate glasses. Journal of Non-Crystalline Solids, 2015. 430: p. 99-107.

48. Fujiwara, H., Spectroscopic ellipsometry: principles and applications. 2007: John Wiley \& Sons.

49. Kirkpatrick, R.J. and R.K. Brow, Nuclear magnetic resonance investigation of the structures of phosphate and phosphate-containing glasses: a review. Solid state nuclear magnetic resonance, 1995. 5(1): p. 9-21.

50. Khor, S., Z. Talib, and W.M. Yunus, Optical properties of ternary zinc magnesium phosphate glasses. Ceramics International, 2012. 38(2): p. 935940.

51. Thornton, J.A., Influence of apparatus geometry and deposition conditions on the structure and topography of thick sputtered coatings. Journal of Vacuum Science \& Technology, 1974. 11(4): p. 666-670.

52. Zhao, Y.D., et al., Surface roughness of alumina films deposited by reactive r.f. sputtering. Thin Solid Films, 1996. 286(1-2): p. 45-48.

53. Kelly, R., On the Role of Gibbsian Segregation in Causing Preferential Sputtering. Surface and Interface Analysis, 1985. 7(1): p. 1-7.

54. Miotello, A., et al., Alkali-Metal Segregation at Glass Surfaces during ElectronIrradiation. Physical Review B, 1991. 43(5): p. 3831-3836.

55. Stan, G.E., et al., Bioactive Glass Thin Films Deposited by Magnetron Sputtering Technique: The Role of Working Pressure. Applied Surface Science, 2010. 256(23): p. 7102-7110.

56. Rao, K.J., Structural Chemistry of Glasses. 2002: Elsevier.

57. Dabas, P., V. Subramanian, and K. Hariharan, Effect of quenching rate on the structure, ion transport, and crystallization kinetics in lithium-rich phosphate glass. Journal of Materials Science, 2014. 49(1): p. 134-141.

58. Singh, S., M.D. Ediger, and J.J. de Pablo, Ultrastable glasses from in silico vapour deposition. Nat Mater, 2013. 12(2): p. 139-144.

59. Kearns, K.L., et al., Influence of substrate temperature on the stability of glasses prepared by vapor deposition. Journal of Chemical Physics, 2007. 127(15): p. 154702-154702.

60. Bauer, T.W. and J. Schils, The pathology of total joint arthroplasty. Skeletal radiology, 1999. 28(9): p. 483-497.

61. Bloebaum, R.D., et al., Complications with hydroxyapatite particulate separation in total hip arthroplasty. Clin Orthop Relat Res, 1994. 298: p. 1926. 
62. Epinette, J.-A. and M.T. Manley, Fifteen years of clinical experience with hydroxyapatite coatings in joint arthroplasty. 2013: Springer.

63. Yang, Y.-C. and E. Chang, Influence of residual stress on bonding strength and fracture of plasma-sprayed hydroxyapatite coatings on Ti-6Al-4V substrate. Biomaterials, 2001. 22(13): p. 1827-1836.

64. Wang, B., et al., The shear strength and the failure mode of plasma-sprayed hydroxyapatite coating to bone: The effect of coating thickness. Journal of biomedical materials research, 1993. 27(10): p. 1315-1327.

65. Buford, A. and T. Goswami, Review of wear mechanisms in hip implants: Paper I - General. Materials \& Design, 2004. 25(5): p. 385-393.

66. Long, M. and H. Rack, Titanium alloys in total joint replacement-a materials science perspective. Biomaterials, 1998. 19(18): p. 1621-1639.

67. Salama, S. and H. El-Batal, Microhardness of phosphate glasses. Journal of noncrystalline solids, 1994. 168(1-2): p. 179-185.

68. Hermansen, C., et al., Densification and plastic deformation under microindentation in silicate glasses and the relation to hardness and crack resistance. Journal of Non-Crystalline Solids, 2013. 364: p. 40-43.

69. Felfel, R., et al., Initial mechanical properties of phosphate-glass fibrereinforced rods for use as resorbable intramedullary nails. Journal of Materials Science, 2012. 47(12): p. 4884-4894.

70. Parsons, A.J., et al., Phosphate glass fibre composites for bone repair. Journal of Bionic Engineering, 2009. 6(4): p. 318-323.

71. Makishima, A. and J. Mackenzie, Direct calculation of Young's moidulus of glass. Journal of Non-Crystalline Solids, 1973. 12(1): p. 35-45.

72. Sharmin, N., et al., Effect of boron oxide addition on fibre drawing, mechanical properties and dissolution behaviour of phosphate-based glass fibres with fixed 40, 45 and 50 mol\% P205. Journal of biomaterials applications, 2014. 29(5): p. 639-653.

73. Teixeira, V., Mechanical integrity in PVD coatings due to the presence of residual stresses. Thin Solid Films, 2001. 392(2): p. 276-281.

74. Stan, G.E., et al., Effect of Anealing Upon the Structure and Adhesion Properties of Sputtered Bio-Glass/Titanium Coatings. Applied Surface Science, 2009. 255(22): p. 9132-9138.

75. Ishii, K. and H. Nakayama, Structural relaxation of vapor-deposited molecular glasses and supercooled liquids. Physical Chemistry Chemical Physics (Incorporating Faraday Transactions), 2014. 16(24): p. 12073-12092.

76. Dawson, K.J., et al., Anisotropic structure and transformation kinetics of vapordeposited indomethacin glasses. The Journal of Physical Chemistry B, 2010. 115(3): p. 455-463.

77. Detor, A.J., et al., Stress and microstructure evolution in thick sputtered films. Acta materialia, 2009. 57(7): p. 2055-2065.

78. Dey, A., et al., Nanoindentation study of microplasma sprayed hydroxyapatite coating. Ceramics International, 2009. 35(6): p. 2295-2304.

79. Nelea, V., et al., Microstructure and mechanical properties of hydroxyapatite thin films grown by $R F$ magnetron sputtering. Surface and Coatings technology, 2003. 173(2): p. 315-322.

80. Kinney, J., et al., Hardness and Young's modulus of human peritubular and intertubular dentine. Archives of Oral Biology, 1996. 41(1): p. 9-13. 
81. Seong, W.-J., et al., Elastic properties and apparent density of human edentulous maxilla and mandible. International journal of oral and maxillofacial surgery, 2009. 38(10): p. 1088-1093.

82. Kolodziejczyk, L., et al., Nanotribology of silver and silicon doped carbon coatings. Diamond and Related Materials, 2016. 67: p. 8-15. 